\title{
Comparative Leaf and Root Transcriptomic Analysis of two Rice Japonica Cultivars Reveals Major Differences in the Root Early Response to Osmotic Stress
}

\author{
Elena Baldoni ${ }^{1,2^{*}}$, Paolo Bagnaresi ${ }^{3}$, Franca Locatelli ${ }^{1}$, Monica Mattana ${ }^{1}$ and Annamaria Genga ${ }^{1 *}$
}

\begin{abstract}
Background: Rice (Oryza sativa L.) is one of the most important crops cultivated in both tropical and temperate regions and is characterized by a low water-use efficiency and a high sensitivity to a water deficit, with yield reductions occurring at lower stress levels compared to most other crops. To identify genes and pathways involved in the tolerant response to dehydration, a powerful approach consists in the genome-wide analysis of stress-induced expression changes by comparing drought-tolerant and drought-sensitive genotypes.

Results: The physiological response to osmotic stress of 17 japonica rice genotypes was evaluated. A clear differentiation of the most tolerant and the most sensitive phenotypes was evident, especially after 24 and $48 \mathrm{~h}$ of treatment. Two genotypes, which were characterized by a contrasting response (tolerance/sensitivity) to the imposed stress, were selected. A parallel transcriptomic analysis was performed on roots and leaves of these two genotypes at 3 and $24 \mathrm{~h}$ of stress treatment. RNA-Sequencing data showed that the tolerant genotype Eurosis and the sensitive genotype Loto mainly differed in the early response to osmotic stress in roots. In particular, the tolerant genotype was characterized by a prompt regulation of genes related to chromatin, cytoskeleton and transmembrane transporters. Moreover, a differential expression of transcription factor-encoding genes, genes involved in hormone-mediate signalling and genes involved in the biosynthesis of lignin was observed between the two genotypes.
\end{abstract}

Conclusions: Our results provide a transcriptomic characterization of the osmotic stress response in rice and identify several genes that may be important players in the tolerant response.

Keywords: Hormones, Lignin, Oryza sativa, Osmotic stress, RNA-Seq analysis, Transcription factors

\section{Background}

Drought is one of the most important environmental constraints affecting plant growth and development and ultimately leads to yield loss. Water deficiency is a global concern because even the most productive agricultural regions can occasionally experience short periods or years of severe drought. Furthermore, irrigation might be restricted in the future because of the competition from other non-agricultural sectors, such as industry and urban areas (Bouman et al. 2007). Moreover,

\footnotetext{
*Correspondence: elena.baldoni@unimi.it; genga@ibba.cnr.it

${ }^{1}$ Institute of Agricultural Biology and Biotechnology - National Research

Council, via Bassini 15, 20133 Milan, Italy

Full list of author information is available at the end of the article
}

drought will continue to become worse in the next decades because of the potential impact of climate change on rainfall patterns and the need to extend the exploitation of marginal lands (Bates et al. 2008). Therefore, the implementation of water management practices and the development of both drought-tolerant varieties and wateruse-efficient crops are key strategies to maintain yields under climate change conditions, extend cultivation to sub-optimal cropping areas and save water for sustainable agriculture. However, the development of droughttolerant varieties still represents a challenging task, being hampered by the occurrence of genotype $\times$ environment interactions, the difficulty of effective drought tolerance screening and a still partial understanding of the 
molecular mechanisms of plant drought tolerance (Richards 1996; Kumar et al. 2008).

When plants perceive stress signals from their surroundings, a number of physiological, biochemical and molecular modifications occur (Krasensky and Jonak 2012). Some of these responses merely represent a consequence of cell damage, while others correspond to adaptive processes plants have evolved to cope with environmental cues. At the molecular level, the expression of a large number of genes is modulated under water stress conditions (Shinozaki and Yamaguchi-Shinozaki 2007; Qin et al. 2011; Yoshida et al. 2014). These genes encode either proteins with a direct role in protecting cell structures (e.g., metabolic enzymes, late embryogenesis-abundant proteins, detoxification enzymes and chaperones), or proteins with a regulatory function (e.g., transcription factors (TFs), protein kinases and other proteins involved in signal transduction) (Valliyodan and Nguyen 2006; Shinozaki and Yamaguchi-Shinozaki 2007; Hadiarto and Tran 2011). In particular, the identification of genes and pathways involved in the tolerant response to dehydration is clearly a crucial step in the development of droughttolerant varieties. A powerful approach, which is increasingly being used to discriminate between drought tolerance-related genes and drought-responsive genes, is to perform genome-wide analyses of stress-induced expression changes by comparing drought-tolerant and drought-sensitive genotypes, rather than performing gene expression experiments on single genotypes (Moumeni et al. 2011; Utsumi et al. 2012; Guimaraes et al. 2012; Degenkolbe et al. 2013). This approach has allowed for the identification of genes with a positive function in enhancing drought tolerance and is potentially useful for the development of molecular markers to accelerate breeding programs.

Rice (Oryza sativa L.) is one of the most important crops cultivated in both tropical and temperate regions, representing the staple food for a large fraction of the world population. Rice is a high water demanding species, using approximately $40 \%$ of the water diverted for irrigation (Lampayan et al. 2015), and rice cultivation is characterized by a low water-use efficiency and a high sensitivity to water deficit, with yield reductions occurring at lower stress levels compared to most other crops. Rice cultivation relies on cropping systems based on different water regimes, from irrigated systems to rainfed lowland and upland rice fields to deep water fields. The increasingly frequent occurrence of drought and the possible future restrictions of water availability for agricultural purposes are among the major challenges to be met to achieve sustainable rice production. Actually, it is estimated that by 2025,15 to 20 million hectares of irrigated rice fields will suffer from some degree of water scarcity (Lampayan et al. 2015). For these reasons, the development of new rice cultivars with a better wateruse efficiency or an enhanced drought tolerance is a primary goal in rice breeding programs. Currently, an increasing number of studies focuses on the identification of drought responsive genes that are differentially regulated in rice genotypes characterized by a contrasting phenotype in response to stress (Degenkolbe et al. 2009; Lenka et al. 2011; Cal et al. 2013; Degenkolbe et al. 2013; Moumeni et al. 2015).

In the present work, a parallel transcriptomic analysis was conducted on two Italian rice genotypes characterized by a contrasting phenotype in response to osmotic stress. RNA-Sequencing was performed separately on leaves and roots to characterize the specific response of these organs in the considered genotypes. The results of this study may contribute to elucidating the mechanisms involved in the rice response to osmotic stress and to identify genes that are putatively responsible for the stress-tolerant phenotype.

\section{Results and Discussion Physiological Response to Osmotic Stress}

To evaluate the physiological response to osmotic stress of 17 japonica rice cultivars, which are currently listed in the Italian National Register, the leaf relative water content (RWC; Table 1) and the leaf electrolyte leakage (EL; Table 2) of plants subjected to $0,3,24$ and $48 \mathrm{~h}$ of $20 \%$ polyethylene glycol (PEG) treatment were measured. The rice cultivars showed different responses to the imposed stress. After 24 and $48 \mathrm{~h}$ of treatment, a clear differentiation of the most tolerant and the most sensitive phenotypes was evident. In particular, after $48 \mathrm{~h}$ of treatment, Carnaroli, Gigante Vercelli, Loto, Maratelli and Vialone Nano resulted to be the most sensitive cultivars, showing both the lowest RWC $(<15 \%)$ and the highest EL ( $>94 \%)$ values, whereas Augusto and Eurosis resulted to be the most tolerant genotypes, showing both the highest RWC values (>80\%) and the lowest EL values $(<40 \%)$. The other cultivars (Thaibonnet, Baldo, Gladio, Koral, Salvo, SISR215, Volano, Arborio, Venere, Asia) exhibited an intermediate phenotype. In a previous study, we investigated the response to osmotic stress of 8 Italian rice cultivars; among them, 6 cultivars analyzed in the present work (Arborio, Augusto, Baldo, Eurosis, Loto and Vialone Nano) were included (Baldoni et al. 2013). In that analysis, Augusto and Eurosis resulted among the most tolerant cultivars, with RWC values $>60 \%$ after $48 \mathrm{~h}$ of treatment, whereas Loto and Vialone Nano resulted the most sensitive cultivars, with RWC values $<15 \%$ after $48 \mathrm{~h}$ of treatment. The present work, in which a higher number of cultivars was analyzed, confirmed the highly tolerant phenotype for Augusto and Eurosis, and the highly 
Table 1 Relative water content (RWC) measurements of rice cultivars

\begin{tabular}{|c|c|c|c|c|c|c|c|c|}
\hline \multirow[b]{2}{*}{$\mathrm{CV}$} & \multicolumn{2}{|l|}{ start } & \multicolumn{2}{|l|}{$3 \mathrm{~h}$} & \multicolumn{2}{|l|}{$24 \mathrm{~h}$} & \multicolumn{2}{|l|}{$48 \mathrm{~h}$} \\
\hline & mean & $p$ & mean & $p$ & mean & $p$ & mean & $p$ \\
\hline Carnaroli & 95.3 & $\mathrm{bcd}$ & 68.3 & abcd & 16.8 & $a b c$ & 14.3 & a \\
\hline Gigante Vercelli & 94.4 & $\mathrm{abcd}$ & 66.9 & $a b c$ & 17.2 & $a b c$ & 12.0 & a \\
\hline Loto & 91.8 & $a$ & 64.6 & $a b$ & 33.9 & abcde & 11.7 & a \\
\hline Maratelli & 92.9 & $a b$ & 63.4 & a & 13.7 & $a b$ & 13.8 & a \\
\hline Vialone Nano & 93.3 & $a b c$ & 62.8 & $a$ & 11.9 & a & 9.2 & a \\
\hline Thaibonnet & 96.7 & $d$ & 84.0 & efg & 39.7 & cdef & 18.5 & $a b$ \\
\hline Baldo & 94.6 & $\mathrm{abcd}$ & 78.1 & defg & 35.7 & bcdef & 23.6 & $a b c$ \\
\hline Gladio & 97.0 & $d$ & 85.6 & $\mathrm{fg}$ & 28.1 & abcd & 31.5 & $a b c$ \\
\hline Koral & 92.9 & $a b$ & 77.9 & defg & 50.6 & defg & 27.0 & $a b c$ \\
\hline Salvo & 96.2 & $\mathrm{~cd}$ & 76.8 & cdef & 30.3 & abcde & 28.1 & $a b c$ \\
\hline SISR215 & 95.3 & bcd & 78.4 & defg & 37.1 & cdef & 30.4 & $a b c$ \\
\hline Volano & 93.9 & $\mathrm{abcd}$ & 74.7 & bcde & 34.4 & abcdef & 26.7 & $a b c$ \\
\hline Arborio & 95.7 & $\mathrm{bcd}$ & 79.8 & efg & 52.8 & efg & 37.6 & $b c$ \\
\hline Venere & 96.4 & $\mathrm{~cd}$ & 87.9 & $g$ & 62.9 & gh & 44.6 & $\mathrm{~cd}$ \\
\hline Asia & 96.1 & $\mathrm{~cd}$ & 85.3 & efg & 57.0 & fgh & 63.5 & de \\
\hline Augusto & 94.3 & $\mathrm{abcd}$ & 76.9 & cdef & 76.6 & hi & 82.4 & ef \\
\hline Eurosis & 94.2 & $\mathrm{abcd}$ & 87.0 & $\mathrm{fg}$ & 89.7 & i & 86.4 & f \\
\hline
\end{tabular}

Data were taken following $0,3,24$ and 48 h of PEG treatment. Each percentage value is the mean of 5 plants. For each sampling time, data were subjected to a one-way analysis of variance to compare the different varieties. Different letters in the same column show significant differences based on a Tukey's test $(p \leq 0.001)$

Table 2 Electrolyte leakage (EL) measurements of rice cultivars

\begin{tabular}{|c|c|c|c|c|c|c|c|c|}
\hline \multirow[b]{2}{*}{$\mathrm{CV}$} & \multicolumn{2}{|l|}{ Start } & \multicolumn{2}{|l|}{$3 h$} & \multicolumn{2}{|l|}{$24 \mathrm{~h}$} & \multicolumn{2}{|l|}{$48 \mathrm{~h}$} \\
\hline & Mean & $p$ & Mean & $p$ & Mean & $p$ & Mean & $p$ \\
\hline Gigante vercelli & 18.6 & $\mathrm{~cd}$ & 41.8 & $\mathrm{~h}$ & 94.8 & $\mathrm{Im}$ & 97.2 & $\mathrm{~h}$ \\
\hline Carnaroli & 16.4 & $a b c$ & 23.8 & $a b c$ & 88.0 & hi & 95.6 & gh \\
\hline Loto & 16.7 & $b c$ & 49.5 & i & 89.7 & il & 94.4 & gh \\
\hline Maratelli & 13.6 & a & 42.0 & $\mathrm{~h}$ & 95.8 & $\mathrm{~m}$ & 95.8 & gh \\
\hline Vialone Nano & 24.4 & $\mathrm{fg}$ & 40.2 & gh & 84.8 & hi & 96.2 & gh \\
\hline Volano & 25.0 & g & 36.2 & g & 83.4 & $\mathrm{~h}$ & 94.0 & gh \\
\hline SISR215 & 21.6 & ef & 31.2 & $f$ & 56.2 & C & 91.6 & fgh \\
\hline Thaibonnet & 22.0 & ef & 30.0 & ef & 67.4 & $f$ & 89.8 & $\mathrm{fg}$ \\
\hline Baldo & 14.6 & $a b$ & 21.2 & $a$ & 65.0 & ef & 85.8 & ef \\
\hline Koral & 20.0 & de & 28.5 & def & 66.7 & ef & 80.3 & de \\
\hline Salvo & 15.8 & $a b c$ & 22.6 & $a b$ & 61.6 & de & 81.2 & de \\
\hline Gladio & 14.2 & $a b$ & 22.2 & $a b$ & 76.0 & g & 78.0 & $d$ \\
\hline Venere & 26.0 & g & 32.0 & f & 52.8 & C & 69.8 & C \\
\hline Arborio & 21.8 & ef & 30.6 & ef & 56.6 & $\mathrm{~cd}$ & 58.4 & $b$ \\
\hline Asia & 16.8 & $b c$ & 23.6 & $a b c$ & 43.8 & $b$ & 55.0 & $b$ \\
\hline Augusto & 18.2 & $\mathrm{~cd}$ & 25.4 & bcd & 27.8 & $\mathrm{a}$ & 30.6 & $\mathrm{a}$ \\
\hline Eurosis & 21.6 & ef & 27.0 & cde & 29.0 & $\mathrm{a}$ & 35.8 & $\mathrm{a}$ \\
\hline
\end{tabular}

Data were taken following 0, 3, 24 and 48 h of PEG treatment. Each percentage value is the mean of 3 plants. For each sampling time, data were subjected to a one-way analysis of variance to compare the different varieties. Different letters in the same column show significant differences based on a Tukey's test $(p \leq 0.001)$ sensitive phenotype for Loto and Vialone Nano in response to osmotic stress.

Based on the obtained physiological results and on the rice grain type classification, Eurosis and Loto (both Long A grain rice cultivars) were selected as tolerant and sensitive genotypes, respectively, for transcriptome analysis, to identify differentially expressed genes (DEGs) and differentially regulated pathways under osmotic stress.

\section{RNA-Seq Data Analysis and Evaluation of DEGs}

RNA samples that were isolated from leaves and roots of Eurosis and Loto genotypes at 3 and $24 \mathrm{~h}$ of osmotic stress treatment were subjected to whole transcriptome sequencing, to analyze the short-term response to osmotic stress. The corresponding control samples were also analysed. Three biological replicates were performed for each rice genotype and condition (48 samples in total). Raw reads (50 bases, single-end) obtained from Illumina HiSeq sequencing were filtered (Illumina passed-filter call), and the fastQC application was employed to detect sequence contaminants. Contaminant-free, filtered reads (trimmed to 43 bases to discard low-quality 3 ' terminal regions) ranging from 17 to 36 million per sample (Additional file 1: Table S1) were mapped with Bowtie 0.12.7 and TopHat 1.4.1 to the rice Nipponbare genome (Ensembl plants release MSU 6.16). Raw read counts were obtained from 
BAM alignment files by counting with HTSeq software. An RPKM (Reads per Kilobase per Million) cut-off value of 0.1 was set to declare a locus expressed resulting in 32,862 and 32,778 loci above the expression cut-off for Eurosis and Loto varieties, respectively. All of the biological replicates exhibited Pearson correlation coefficients above 0.9 , indicating a good level of reproducibility among biological replicates (Fig. 1 and Additional file 2: Table S2).

To identify DEGs, the R package DESeq was employed. Two countset instances were created for Eurosis and Loto.
The false discovery rate (FDR) threshold was set to 0.001 , and gene dispersion values were calculated using the "maximum" mode. Given the large number of DEGs detected in all of the contrasts, a threshold of 3-fold expression change was further established to focus on a subset of DEGs showing highest modulation.

Gene expression changes for 10 selected genes, that were identified as DEGs during the RNA-Seq experiments and were reported to be involved in the osmotic stress response, were validated using qRT-PCR. The

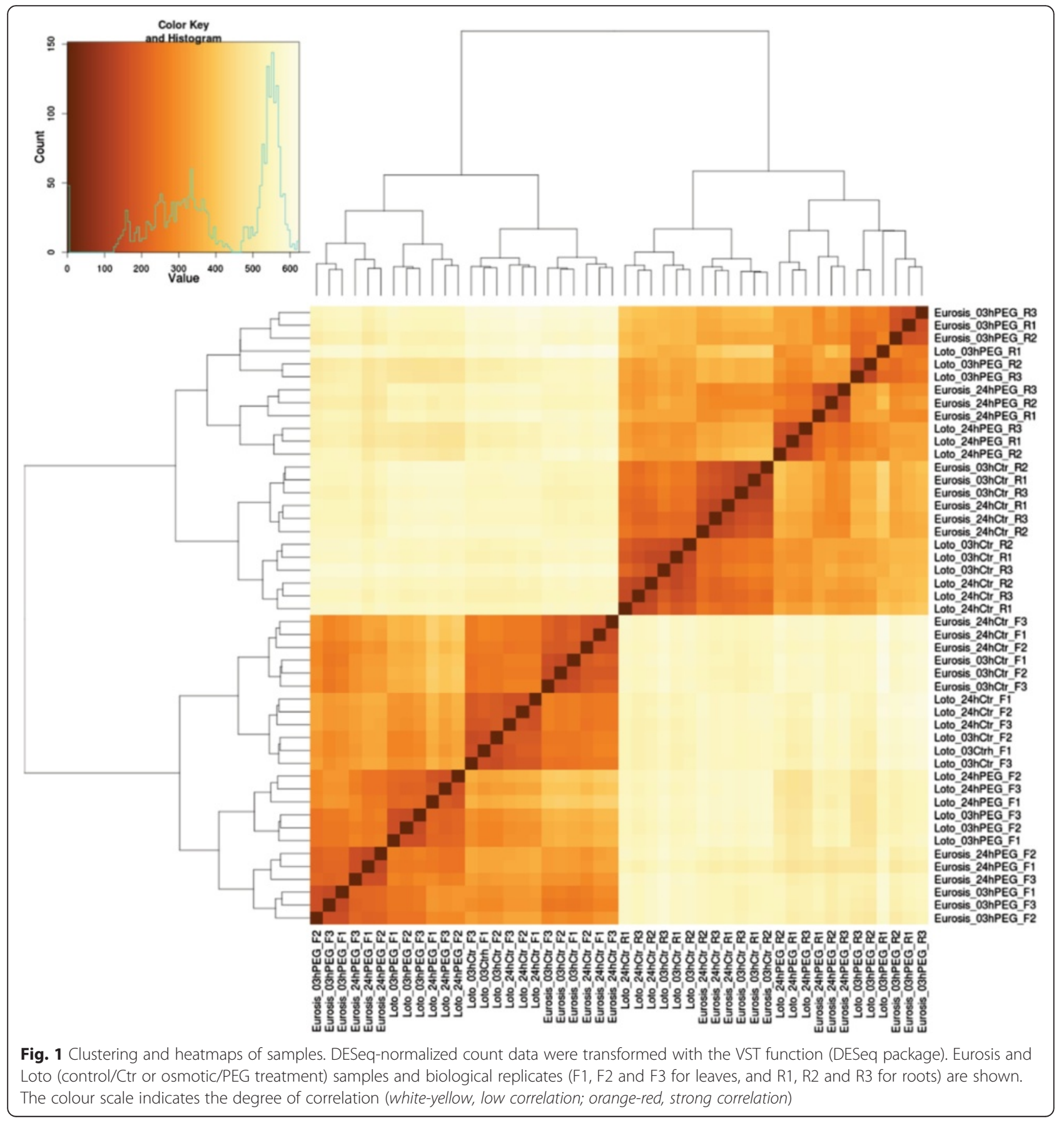


comparison between RNA-Seq and qRT-PCR fold change data, which was obtained by a regression analysis, revealed a substantial agreement in the extent of the osmotic stress-induced variations in transcript accumulation for the 10 tested genes (Fig. 2 and Additional file 3: Table S3). The transcript levels of 6 of these genes (LOC_ Os01g07120, LOC_Os01g66120, LOC_Os02g44870, LO C_Os04g43680, LOC_Os04g45810 and LOC_Os10g33 810 ) have been previously analysed using qRT-PCR in rice samples of Eurosis and Loto plants under the same stress conditions (Baldoni et al. 2013). The comparison between qRT-PCR data presented here and in the previous work revealed comparable stress-induced fold changes, indicating a good reproducibility of the osmotic stress experiments (data not shown).

The RNA-Seq analysis showed that osmotic stress caused significant changes in gene expression in the roots and leaves of both genotypes (Fig. 3, Table 3 and Additional file 4: Table S4). In particular, $3 \mathrm{~h}$ of osmotic stress led to a substantial modulation of gene expression in the roots of the tolerant genotype Eurosis (6007 genes), whereas fewer DEGs were called in the roots of the susceptible genotype Loto (3962 genes). At $24 \mathrm{~h}$ of treatment, a similar number of DEGs was found in Eurosis and Loto roots (3065 and 3102 genes, respectively). In the leaves, a similar number of DEGs was found in the two genotypes, both at 3 and $24 \mathrm{~h}$ of osmotic stress treatment (2977 and 4223 in Eurosis, and 3088 and 4813 in Loto, respectively) (Table 3). The stress response of the two cultivars consisted of a common and a specific component (Fig. 3 and Table 3). In particular, the specific response was prominent in the roots. Indeed, in the roots at $3 \mathrm{~h}$ of stress treatment, 2499 DEGs (representing only $34 \%$ of the total DEGs in this tissues/time of treatment) were common to Eurosis and Loto, whereas $66 \%$ were specific to one or the other genotype (47 and $19 \%$ to Eurosis and Loto, respectively). Only 53 DEGs (0.7\%) were oppositely modulated in the two genotypes in this tissue/time of treatment. It is noteworthy that in all of the other contrasts, no oppositely modulated DEGs were observed. In $24 \mathrm{~h}$-treated roots, a proportion of $41 \%$ of the DEGs was common to Eurosis and Loto, whereas $59 \%$ were specific to one or the other genotype. In the leaves, the proportion of common DEGs was higher than in the roots, with 51 and $54 \%$ at 3 and $24 \mathrm{~h}$ of stress treatment, respectively (Fig. 3 and Table 3). Regarding up-and down-regulated genes, the mean expression vs. logfold change plots (MA-plots, Fig. 4) illustrated that, among the DEGs, the proportion of up- and down-regulated genes was substantially similar in all the control vs. treated comparisons, with the exception of the $3 \mathrm{~h}$ root samples of Eurosis, in which the number of up-regulated genes (61.6\% of all DEGs) was higher than the number of down-regulated genes (38.4\%). In summary, major differences between the responses of the two cultivars were observed at $3 \mathrm{~h}$ of osmotic treatment in roots, where a higher number of genes were significantly regulated and where the common response was less represented than in the other tested conditions.

As mentioned above, DEGs showing an opposite modulation between the two genotypes were found only in 3 h-treated roots; that is, 4 DEGs were up-regulated in Eurosis and down-regulated in Loto, and 49 DEGs were up-regulated in Loto and down-regulated in Eurosis (Table 3 and Additional file 5: Table S5). Thus far, no literature data are available on the function of the 4 genes that were up-regulated in Eurosis and downregulated in Loto; only little information is present in the literature about some of the 49 genes that were upregulated in Loto and down-regulated in Eurosis. In particular, LOC_Os01g06500 codes for a lectin-like

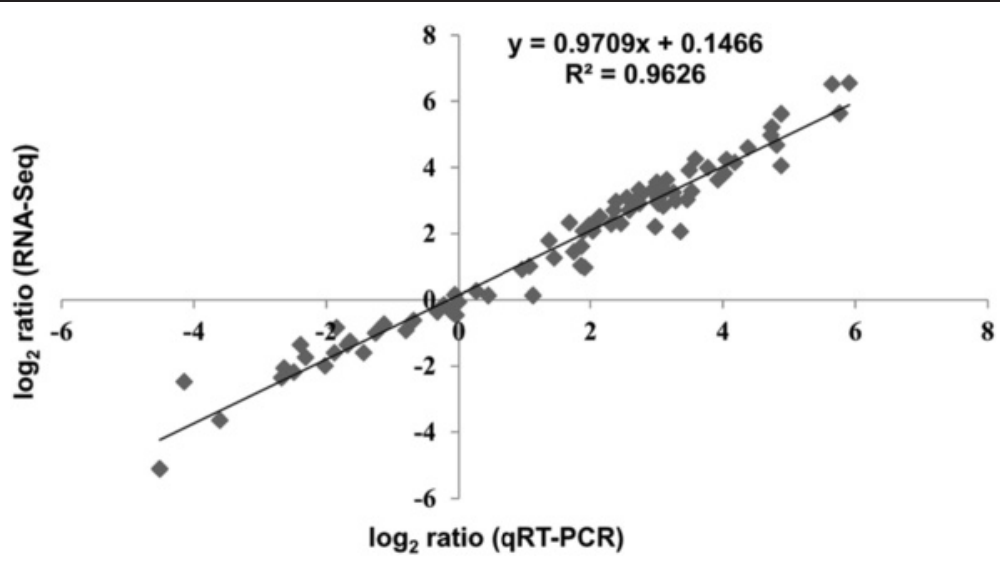

Fig. 2 Validation of the expression of selected genes from RNA-Seq using qRT-PCR. Fold changes in gene expression were transformed to a log 2 scale. The qRT-PCR data $\log _{2}$-values (X-axis) were plotted against the RNA-Seq $\log _{2}$ values ( $Y$-axis). The function of the regression line and the $R^{2}$ value are shown 


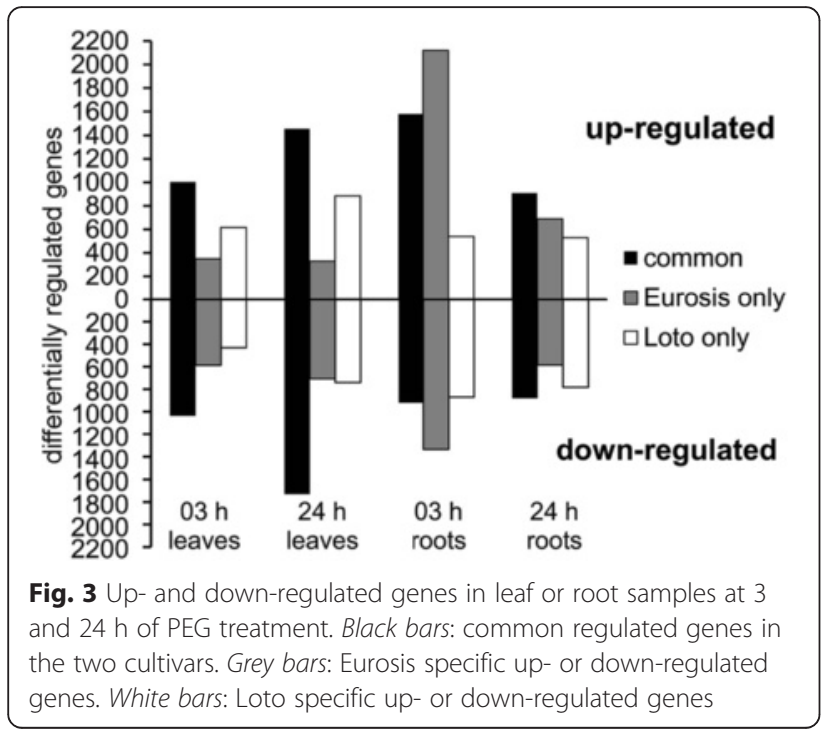

protein, and its expression correlated with the isoprenoid biosynthetic pathway (Suzuki et al. 2007). In rice, the salt-inducible gene SalT encodes a cytoplasmic mannose-binding lectin, whose expression increases after salt or drought stress (de Souza Filho et al. 2003). In general, the expression of lectin-encoding genes may be regulated under abiotic or biotic stress conditions, and a putative role for these genes in plant stress response has been proposed (Rüdiger and Gabius 2001; Van Damme et al. 2004). Moreover, among these 49 genes, some putative TF-encoding genes were present, namely, 1 MYB (LOC_Os02g17190), three putative PHD finger family proteins (LOC_Os03g53630, LOC_Os11g29240 and LO C_Os12g24540) and one putative bZIP (LOC_Os0 3g20530). These genes may be involved in the upstream regulation of the osmotic stress response and may have a crucial role in establishing a different response to the imposed stress in the two genotypes.

\section{Gene Ontology Enrichment Analysis of RNA-Seq Data}

Gene ontology (GO) enrichment analysis of DEGs in the various contrasts was conducted to reveal biological trends differentiating tolerant and susceptible genotypes. The goseq bioconductor package (Robinson and Oshlack 2010) was used to account for the RNA length bias that is typical of RNA-Seq approaches (Oshlack and Wakefield 2009). Both common and genotype-specific enriched terms were identified, confirming the presence of a consistent common response to osmotic stress and genotype-specific responses, as observed in the analysis of DEGs (Fig. 3).

\section{Common Enriched GO Terms}

Sixty-one enriched GO terms were shared by the 2 rice genotypes in all of the analysed tissues and treatments (Additional file 6: Table S6). Among the 21 GO terms related to Biological Processes (BP), some were consistent with responses to water/osmotic stress; these included "response to water deprivation" (GO:0009414), "response to water stimulus" (GO:0009415) and "response to stress" (GO:0006950). Moreover, several common GO terms were related to the response to abiotic stresses, such as "response to oxidative stress" (GO:0006979), "response to cold" (GO:0009409), "response to wounding" (GO:0009611), "response to salt stress" (GO:0009651) and "response to freezing" (GO:0050826). This result was not unexpected because the existence of cross-talk among pathways involved in the response to different abiotic stresses is well known (Qin et al. 2011; Nakashima et al. 2014).

Moreover, the GO terms "response to abscisic acid stimulus" (GO:0009737) and "cellular response to abscisic acid stimulus" (GO:0071215) were shared by all of the samples, and this is consistent with the well known pivotal role of abscisic acid (ABA) signalling in the response to osmotic stress (Fujita et al. 2011). Additional GO terms related to hormone signalling were shared by all of the root samples but not by leaf samples, or vice-versa; in the roots, two GO terms were related to salicylic acid and jasmonic acid-mediated responses (GO:0009751 and GO:0009753, respectively), whereas the GO terms "response to ethylene stimulus" (GO:0009723) and "indolebutyric acid metabolic process" (GO:0080024) were shared only by the leaf samples.

The enriched GO terms shared by all of the root samples or by all of the leaf samples were 20 and 70, respectively, confirming a prominent common response in leaves. Water stress highly affects the photosynthetic

Table 3 Summary of the total number of DEGs, DEGs common to both cultivars and cultivar-specific DEGs

\begin{tabular}{|c|c|c|c|c|c|c|}
\hline \multirow[t]{2}{*}{ Tissue } & \multirow[t]{2}{*}{ Contrasts } & \multicolumn{2}{|c|}{ Total number of DEGs } & \multirow[t]{2}{*}{ Common DEGs } & \multicolumn{2}{|c|}{ Specific DEGs } \\
\hline & & Eurosis & Loto & & Eurosis & $\overline{\text { Loto }}$ \\
\hline Roots & $3 \mathrm{~h}$ control vs. $3 \mathrm{~h}$ stress & 6007 & 3962 & $2552^{a}$ & 3455 & $\overline{1410}$ \\
\hline Roots & $24 \mathrm{~h}$ control vs. $24 \mathrm{~h}$ stress & 3065 & 3102 & 1789 & 1276 & 1313 \\
\hline Leaves & 3 h control vs. 3 h stress & 2977 & 3088 & 2040 & 937 & 1048 \\
\hline Leaves & $24 \mathrm{~h}$ control vs. $24 \mathrm{~h}$ stress & 4223 & 4813 & 3187 & 1036 & 1626 \\
\hline
\end{tabular}

${ }^{a}$ Among the 2552 common DEGs, 53 genes were oppositely regulated between the 2 genotypes, whereas 2499 were modulated in the same manner in the 2 genotypes 

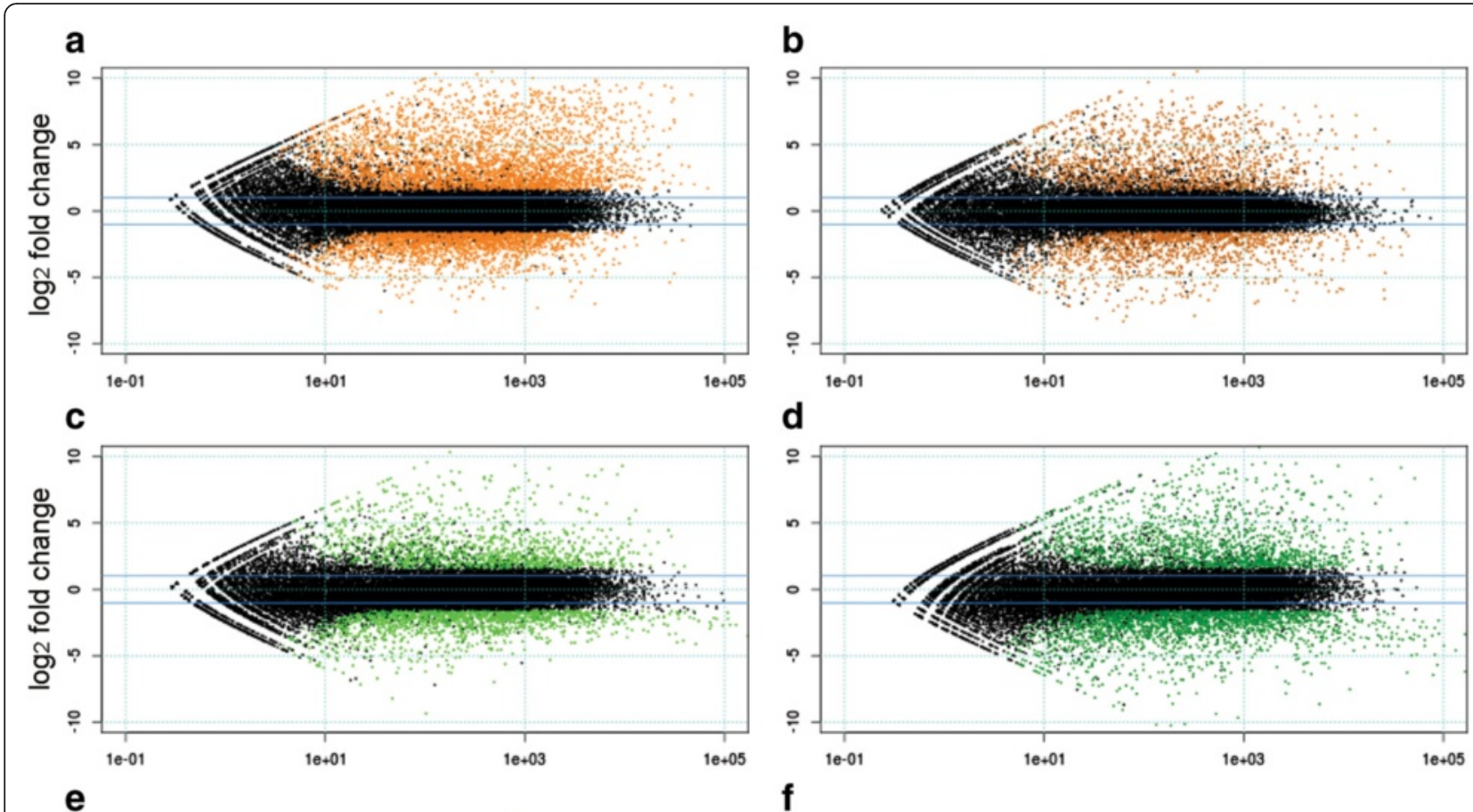

d
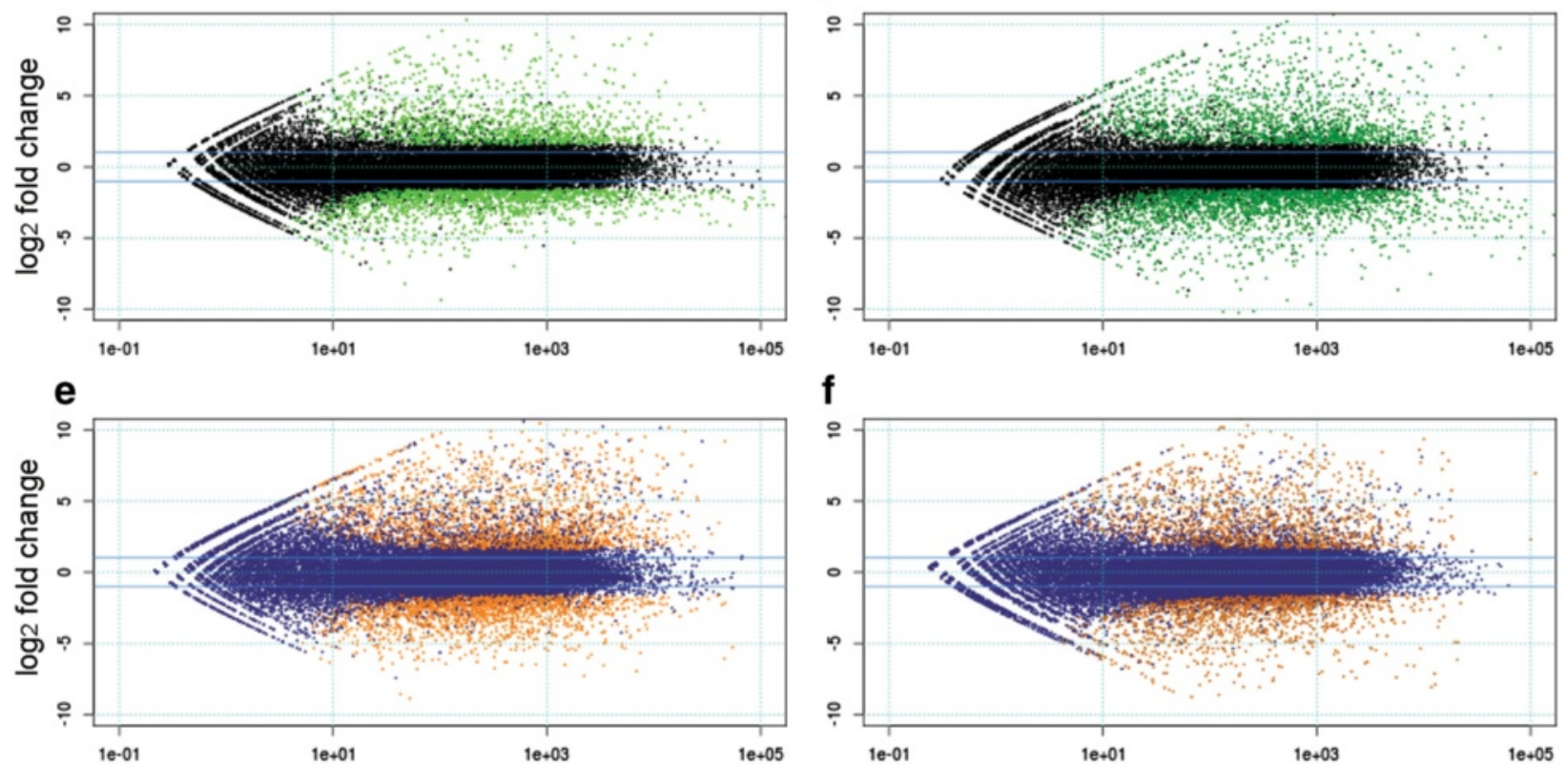

g

h
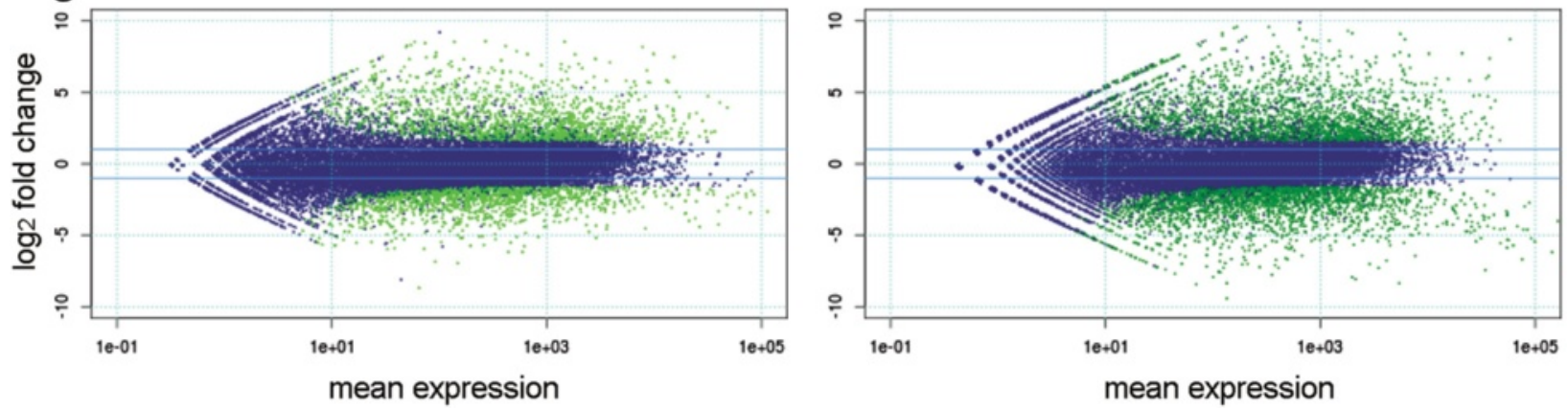

Fig. 4 Mean expression vs. log fold change plots (MA-plots) of Eurosis and Loto samples. Mean expression vs. log fold change plots (MA-plots) were computed for Eurosis (plotted in black; $\mathbf{a}-\mathbf{d}$ ) and Loto (plotted in blue; $\mathbf{e}-\mathbf{h}$ ) contrasts. Normalised expression mean values are plotted vs. $\log _{2}$ fold changes. Called DEGs (FDR $<0.001$ and fold change $>3$ ) are plotted in orange for root samples $(\mathbf{a}, \mathbf{b}$, e and $\mathbf{f})$ and in green for leaf samples (c, d, $\mathbf{g}$ and $\mathbf{h}$ )

processes (Chaves et al. 2009). As expected, many enriched GO terms common to leaf samples were related to photosynthesis (Additional file 6: Table S6). Because of the inhibition of photosynthesis during stress, plants must mobilize energy from storage resources, such as carbohydrates, fatty acids and proteins (Shu et al. 2011). Actually, some GO terms related to fatty acid metabolism were shared by leaf samples of the 2 genotypes, namely, "lipid metabolic process" (GO:0006629), "fatty acid biosynthetic process" (GO:0006633) and "lipid biosynthetic process" (GO:0008610) (Additional file 6: Table S6). 


\section{Genotype-Specific Enriched GO Terms}

Several GO terms were genotype-specific (i.e., enriched GO terms from one genotype/organ/treatment missing in the alternative genotype in the same organ/treatment). Additional file 7: Table S7 reports all of the enriched GO terms for the contrasts with accompanying enrichment $p$ values resulting from goseq analysis. Figures 5 and 6 depict genotype-specific barplots. Because DEG analysis found that the genotype-specific response was prominent in roots, our analysis mainly focused on root samples.

\section{Stress and Hormone-Related GO Terms}

Some enriched GO terms specific to either the Eurosis or the Loto genotype were related to osmotic stress

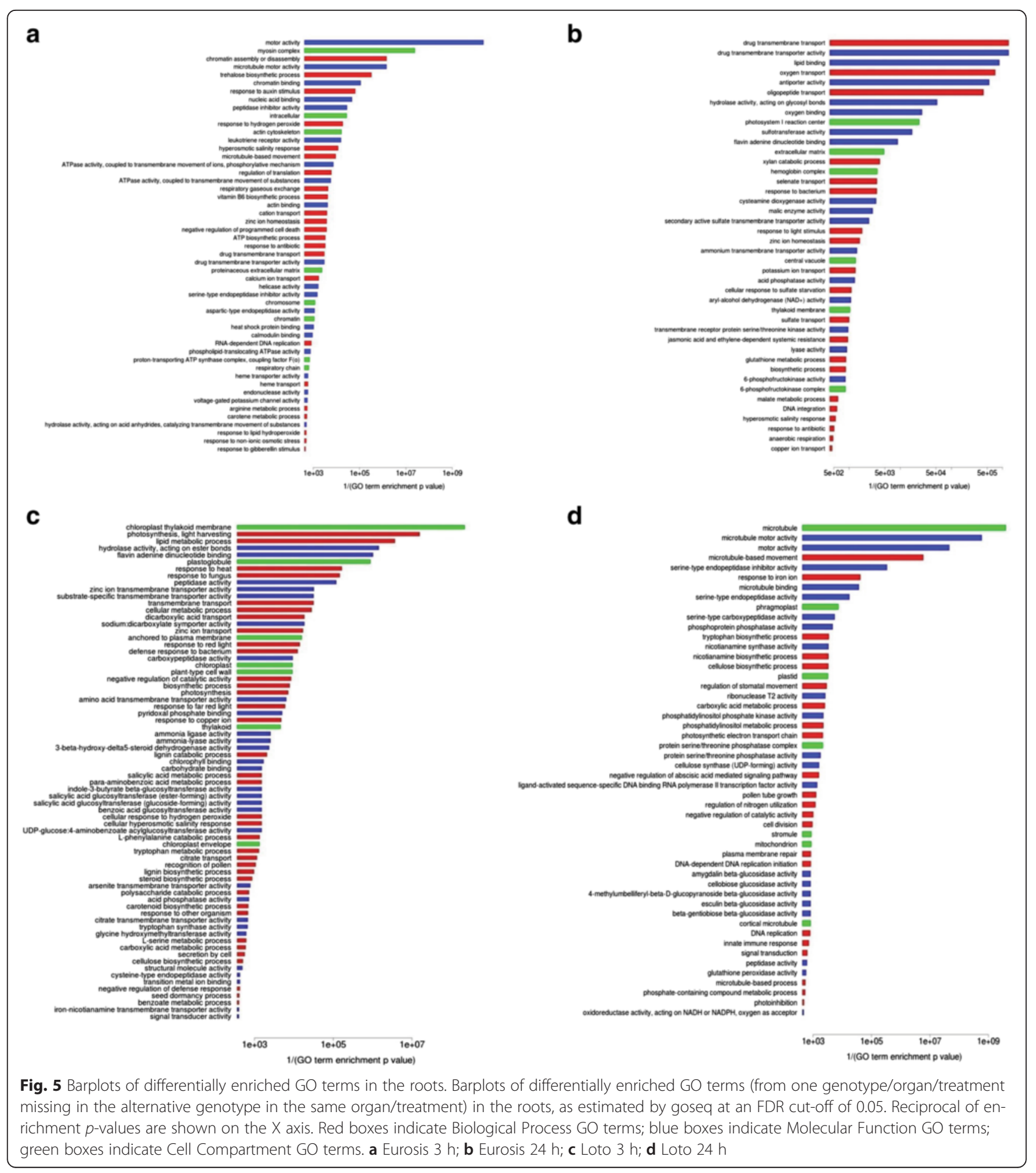



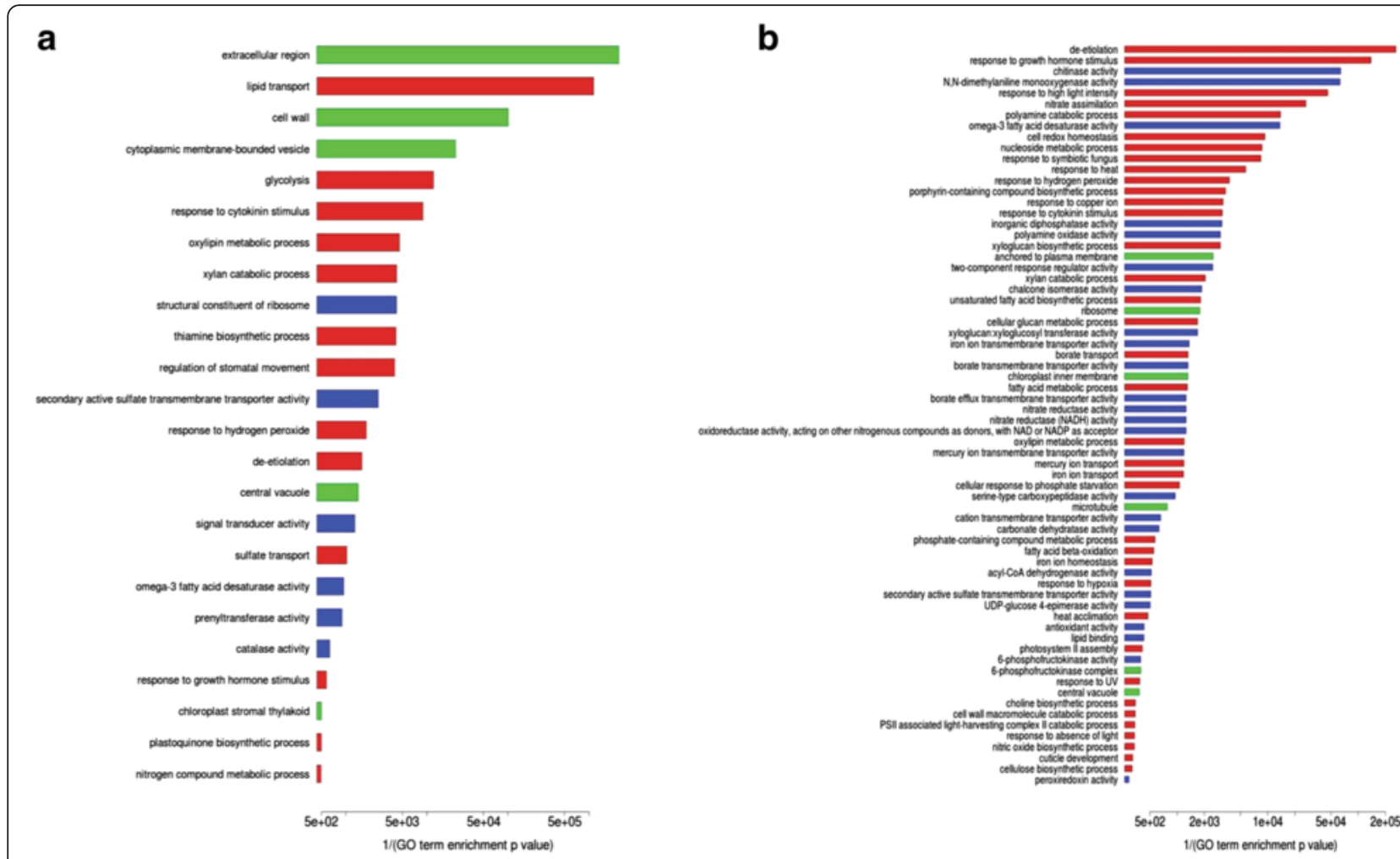

C

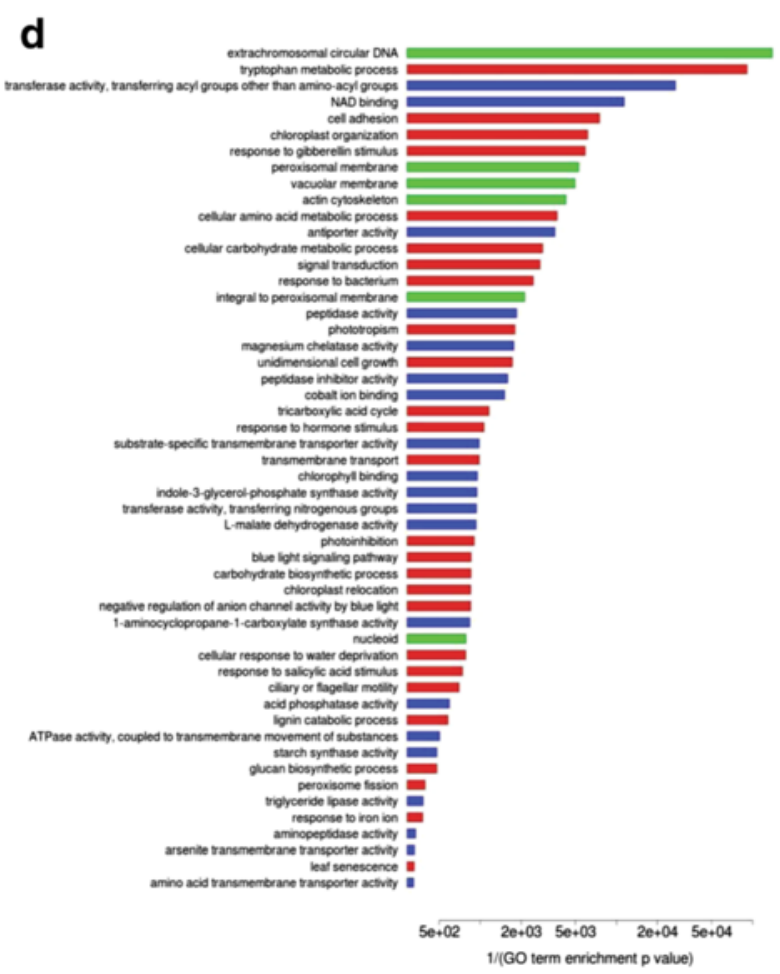

Fig. 6 Barplots of differentially enriched GO terms in the leaves. Barplots of differentially enriched GO terms (from one genotype/organ/treatment missing in the alternative genotype in the same organ/treatment) in the leaves, as estimated by goseq at an FDR cut-off of 0.05 . Reciprocal of enrichment $p$-values are shown on the $\mathrm{X}$ axis. Red boxes indicate Biological Process $\mathrm{GO}$ terms; blue boxes indicate Molecular Function GO terms; green boxes indicate Cell Compartment GO terms. a Eurosis 3 h; b Eurosis 24 h; c Loto 3 h; d Loto 24 h 
response, i.e., "trehalose biosynthetic process" (GO:000 5992), "response to non-ionic osmotic stress" (GO:001 0335) and "hyperosmotic salinity response" (GO:004 2538) in Eurosis roots (Fig. 5a and b); "cellular hyperosmotic salinity response" (GO:0071475) in Loto roots (Fig. 5c); "choline biosynthetic process" (GO:0042425) in Eurosis leaves (Fig. 6b); "proline biosynthetic process" (GO:0006561), "response to abiotic stimulus" (GO:000 9628 ) and "cellular response to water deprivation" (GO:0 042631) in Loto leaves (Fig. 6c and d). Some genes belonging to these GO terms may play a role in the different response of the two genotypes. Among them, LOC_Os03g04570, which was up-regulated only in Eurosis $3 \mathrm{~h}$-treated roots and belonged to the GO term GO:0042538 (Additional file 7: Table S7), codes for a putative peptide transporter (PTR). The PTR family consists of di/tripeptides transporters, and their role in plants is not yet well defined (Saier et al. 2006). This gene is similar to AtPTR3 (AT5G46050), whose expression is induced by salt stress and mechanical wounding and is regulated by jasmonic acid and salicylic acid (Karim et al. 2005; Karim et al. 2007). Another interesting gene is LOC_Os07g01020, which was up-regulated in Eurosis $3 \mathrm{~h}$ - and $24 \mathrm{~h}$ treated roots and in Loto 24 h-treated roots and belonged to the GO terms GO:0010335 and GO:0042538 (Additional file 7: Table S7). This gene codes for a putative SOR/SNZ family protein that has high homology with the pyridoxine synthase gene AT5G01410 (Chen et al. 2014). Interestingly, Jeong et al. (2013) observed that in transgenic rice plants over-expressing OsNAC5 under the control of a rootspecific promoter, LOC_Os07g01020 was up-regulated together with other genes implicated in root growth and development. These plants showed a higher grain yield under drought conditions compared to wild-type plants and an increased root diameter, which could contribute to the enhanced drought tolerance. In our work, the specific induction of LOC_Os07g01020 in Eurosis 3 h-treated roots suggests a possible role for this gene in the early response to osmotic stress of this genotype.

Moreover, several enriched GO terms specific to Eurosis or Loto were related to hormone metabolism (Figs. 5 and 6, Additional file 7: Table S7). Some genes belonging to these GO terms may have a role in the different responses of the two genotypes. For instance, a MYB gene (LOC_Os01g34060) belonging to GO terms related to the response to auxin and gibberellin stimulus (GO:0009733 and GO:0009739, respectively) was up-regulated in Eurosis roots after $3 \mathrm{~h}$ of treatment and in Loto roots after $24 \mathrm{~h}$, suggesting a delay in the Loto response (Additional file 7: Table S7).

\section{Chromatin-Related GO Terms}

Among GO terms specifically enriched in $3 \mathrm{~h}$-treated roots of the tolerant genotype Eurosis, 5 were associated with chromatin (Fig. 5a and Additional file 7: Table S7), namely, "chromatin" (GO:0000785), "chromatin binding" (GO:0003682), "helicase activity" (GO:0004386), "chromosome" (GO:0005694) and "chromatin assembly or disassembly" (GO:0006333). The enrichment of these GO terms was due to the statistically significant modulation of 71 genes (12 up- and 59 down-regulated), which occurred exclusively in Eurosis. Notably, only 1 out of the upregulated genes and 3 out of the down-regulated genes were listed among the DEGs in the 24 h-treated root samples, suggesting that the transcriptomic response associated with chromatin-related processes is an early and transient response in the tolerant cultivar Eurosis.

Globally, the most represented protein family encoded by DEGs annotated within chromatin-related GO categories was the helicase protein superfamily. Helicases are molecular motors that mainly use the energy derived from ATP hydrolysis to bind, unwind or remodel energetically stable double-stranded DNA (DNA helicases) or local RNA secondary structures (RNA helicases). They are central players in virtually all facets of nucleic acid metabolism, and may play essential roles in the response to stress conditions (Vashisht and Tuteja 2006; Tuteja et al. 2013; Zhu et al. 2015).

In rice, $40 \mathrm{Snf} 2$ proteins, which are ATP-dependent chromatin remodelling factors, have been identified, and some of these proteins were affected by stress treatments (Hu et al. 2013). In our 3 h-treated root dataset, 19 out of the 40 Snf2 genes were listed among the DEGs. Among them, 3 genes were up-regulated exclusively in Loto, whereas the other 16 were down-regulated (14 only in Eurosis, 1 only in Loto and 1 in both genotypes). One of the genes specifically down-regulated in Eurosis 3 h-treated roots was LOC_Os06g08480, which is annotated as the CHD3-type chromatin-remodelling factor PICKLE. Interestingly, a role of the PICKLE factor in balancing osmotic stress responses during seed germination has been well demonstrated in Arabidopsis (Perruc et al. 2007). Li et al. (2011) found that LOC_Os06g08480 and another down-regulated Snf2 gene in Eurosis 3 h-treated roots, namely, LOC_Os01g44990, were induced by several abiotic stresses, including PEG-mediated osmotic treatment, in the sensitive cultivar Zhonghua11.

Another represented protein family encoded by DEGs that are annotated within chromatin-related GO categories was the histone protein family. Notably, in our dataset, 7 DEGs annotated as histone proteins were exclusively up-regulated in Eurosis, and 1 was downregulated in Loto. Recent studies have reported that chromatin regulation, and, in particular, histone modification and DNA methylation, are key elements of the 
transcriptional response to abiotic stresses, such as water deficit, high-salinity, and temperature shifts. However, it still remains unclear how transcriptional changes and chromatin changes are linked (Kim et al. 2015).

Among the DEGs, which are annotated with chromatin-related GO terms, 2 showed an opposite regulation in the two cultivars, LOC_Os02g04050 and LOC_Os02g50370, both being down-regulated in Eurosis and up-regulated in Loto (Additional file 4: Table S4). The former is annotated in MSU 6.16 as a putative chromosome segregation protein and the latter as a putative helicase domain-containing protein (Additional file 4: Table S4). To our knowledge, no function in response to any abiotic stress has been reported for these two genes.

It is currently understood that the regulation of abiotic stress responsive genes is related to chromatin alterations. Consistently, our results suggest that chromatin remodelling processes occur in response to osmotic stress and may contribute to differentiating the response between the tolerant and the sensitive cultivar.

\section{Cytoskeleton-Related GO Terms}

In 3 h-treated root samples, 6 GO categories specifically enriched in the Eurosis genotype were related to the cytoskeleton (Fig. 5a and Additional file 7: Table S7), namely, "motor activity" (GO:0003774), "microtubule motor activity" (GO:0003777), "actin binding" (GO:0003779), "microtubulebased movement" (GO:0007018), "actin cytoskeleton" (GO:0015629) and "myosin complex" (GO:0016459). A total of 57 DEGs (21 up-regulated and 36 down-regulated) were responsible for the enrichment of these GO terms in Eurosis $3 \mathrm{~h}$-treated roots. Their expression did not significantly change in Loto $3 \mathrm{~h}$-treated roots. Among the 36 down-regulated DEGs, several genes are annotated either as kinesins (16 genes) or myosins (9 genes), and few additional genes encode actin regulatory proteins, such as formin, villin, and SCAR-like proteins. Notably, 11 out of these 36 genes were significantly down-regulated in Loto roots after $24 \mathrm{~h}$ of treatment, thus suggesting a delay in the response of the sensitive cultivar in comparison to the tolerant one.

Interestingly, some genes associated with these $\mathrm{GO}$ terms showed an opposite regulation in the $3 \mathrm{~h}$-treated roots of the two genotypes, all of them exhibiting a down-regulation in Eurosis and an up-regulation in Loto. Among them, two genes belong to the myosin gene family, namely, LOC_Os01g51632 and LOC_Os01g51634. One additional gene, LOC_Os03g06510, was annotated as KIP1. Kiprelated proteins (KRPs) play a central role in the regulation of the cell cycle and differentiation through the modulation of cyclin-dependent kinases. In Arabidopsis, the overexpression of a member of the KRP family, KRP2, prevents pericycle activation and reduces the number of lateral roots, suggesting a significant role of KRP2 in the regulation of early lateral root initiation (Himanen et al. 2002). Another KRP protein, ICK3/KRP5, is a positive regulator of both cell growth and endoreduplication in roots (Wen et al. 2013). Some studies analysed the relationship between drought stress and the expression of the KRP genes involved in the reprogramming of cell proliferation and cell expansion in leaves (Claeys and Inze 2013; Guan et al. 2014). To our knowledge, no data are available in the literature on a correlation between the expression of KRP genes in roots and the tolerance to water stress.

Three additional genes, which showed an opposite regulation in the $3 \mathrm{~h}$-treated roots of the two genotypes, belong to the kinesin gene family, namely, LOC_Os06g36080, LOC_Os07g44400 and LOC_Os09g25380. Kinesins are microtubule-based motor proteins that are ubiquitous in all eukaryotic organisms and use the energy derived from ATP hydrolysis to move along the cytoskeletal elements of microtubules. Kinesins are involved in microtubule organization, organelle and vesicle transport, cellulose microfibril order, and ultimately contribute to cell division, cell growth and the cross-talk of microtubules and actin microfilaments ( $\mathrm{Li}$ et al. 2012). Recently, a kinesin-like calmodulin-binding protein has been reported to be involved in the signalling network that negatively regulates root growth in Arabidopsis (Humphrey et al. 2015). Considering the kinesin encoding DEGs that were genotype-specific in $3 \mathrm{~h}$-treated roots, 16 were down-regulated in Eurosis and 6 were up-regulated in Loto. Notably, all of the kinesin encoding DEGs showed either a downregulation in Eurosis or an up-regulation in Loto. This differential regulation of kinesin-encoding genes observed in $3 \mathrm{~h}$-treated roots of Eurosis and Loto suggested that this protein family affects the root growth in a genotype-specific manner, thus contributing to the different osmotic stress phenotypes (tolerance/sensitivity) of the 2 cultivars.

\section{Transmembrane Transport-Related GO Terms}

Six enriched GO terms specific to the tolerant genotype Eurosis in the roots at $3 \mathrm{~h}$ of stress treatment were related to transmembrane transport (Fig. 5a and Additional file 7: Table S7), namely, "phospholipid-translocating ATPase activity" (GO:0004012), "drug transmembrane transport" (GO:0006855), "drug transmembrane transporter activity" (GO:0015238), "ATPase activity, coupled to transmembrane movement of ions, phosphorylative mechanism" (GO:0015662), "hydrolase activity, acting on acid anhydrides, catalyzing transmembrane movement of substances" (GO:0016820) and "ATPase activity, coupled to transmembrane movement of substances" (GO:0042626). Thirty-three genes were responsible for the enrichment of these GO terms in the tolerant cultivar. Among them, 10 genes were significantly up-regulated only in Eurosis $3 \mathrm{~h}$ - 
treated roots, including 7 genes encoding multidrug and toxic compound extrusion (MATE) family proteins and 2 genes encoding ATP-binding cassette $(\mathrm{ABC})$ transporter family proteins, whereas 23 genes were specifically downregulated in Eurosis 3 h-treated roots, including 12 genes encoding $\mathrm{ABC}$ transporter family proteins. $\mathrm{ABC}$ and MATE proteins represent the two largest families of active transporters that have been characterized in plants thus far. $A B C$ proteins are primary transporters that mediate the energy-driven transport of a large and diverse multitude of substrates across biological membranes. $A B C$ transporters play key roles in many physiological processes, such as plant development and plant nutrition, and in stress response (Moons 2008; Matsuda et al. 2012; Jarzyniak and Jasinski 2014; Nguyen et al. 2014; Saha et al. 2015). In the rice genome, 133 genes coding for $A B C$ transporters have been identified (Saha et al. 2015). In our study, in 3 h-treated roots, 15 out of the $133 \mathrm{ABC}$ transporter genes were modulated in the same way in the two cultivars, 4 and 7 ABC transporter genes were specifically up-regulated in Eurosis and Loto, respectively, and 14 and $3 \mathrm{ABC}$ transporter genes were specifically down-regulated in Eurosis and Loto, respectively. Among the 4 Eurosisspecific up-regulated genes, the OsABCG22 gene (LOC_Os09g29660) is induced by mannitol and by ABA treatments in rice roots (Matsuda et al. 2012). Moreover, Nguyen et al. (2014) found that drought stress induced this gene in the leaves. Our results are consistent with these data, as this gene was also up-regulated in our leaf samples, both at 3 and $24 \mathrm{~h}$ of stress treatment.

In addition, the superfamily of MATE proteins represents one of the largest transporter families in plants, with more than 50 MATE genes in the rice genome. MATEs are secondary active transporters; in plants they have many physiological functions, such as the accumulation of secondary metabolites, aluminium detoxification and iron translocation (Takanashi et al. 2014; Jarzyniak and Jasinski 2014). Some MATEs are involved in hormone signalling in Arabidopsis, such as AtEDS5, which is responsible for intracellular salycilic acid transport, and AtDTX50, which functions as an ABA efflux transporter and plays a role in ABA-mediated growth inhibition and responses to drought conditions (Takanashi et al. 2014). In our study, among the 50 genes annotated as MATE efflux family proteins or MATE domain containing proteins, 8 DEGs (7 up- and 1 down-regulated) were specific to Eurosis 3 h-treated roots, and 2 DEGs (both down-regulated) were specific to Loto $3 \mathrm{~h}$-treated roots. To our knowledge, no data are available in the literature on a putative role for any of these MATE efflux genes in water stress response. However, the observed stress-mediated regulation of several MATE genes suggests a possible role for some of them in the response to osmotic stress.
Finally, LOC_Os06g12876, which belongs to the GO terms GO:0016820, was 1 of the 49 genes oppositely modulated (down- and up-regulated in Eurosis and Loto, respectively) in $3 \mathrm{~h}$-treated roots (Table 3 ). This gene is annotated in RAP-DB as an "ATPase, F1/V1/A1 complex, alpha/beta subunit”. Thus far, no data are available on the putative function of this gene.

\section{Oxygen-Related GO Terms}

In Eurosis 24 h-treated roots, 5 enriched GO terms were related to oxygen (Fig. 5b), namely, "response to hypoxia" (GO:0001666), "anaerobic respiration" (GO:0009 061), "oxygen transport" (GO:0015671), "oxygen binding" (GO:0019825) and "haemoglobin complex" (GO:0005833). The rice genome contains five genes encoding nonsymbiotic haemoglobins (ns-Hbs), namely OsNSHB1 to OsNSHB5 (LOC_Os03g13140, LOC_Os03g12510, LOC_ Os03g13150, LOC_Os03g13160 and LOC_Os05g44140, respectively) (Garrocho-Villegas et al. 2008), and one gene encoding a putative haemoglobin-like protein $\mathrm{HbO}$ (LOC_Os06g39140). Notably, 4 out of the 5 genes coding for ns-Hbs (OsNSHB1-4) and the putative $\mathrm{HbO}$-encoding gene were up-regulated in $24 \mathrm{~h}$-treated roots only in Eurosis, suggesting a possible role of this class of molecules in the differential response of the two genotypes to the treatment. The ns-Hbs are localized in diverse plant organs, their expression is differently regulated under stress conditions, and their apparent function in vivo is to modulate the levels of ATP and nitric oxide (ns-Hbs class 1) or to facilitate the diffusion of $\mathrm{O}_{2}$ (ns-Hbs class 2) (GarrochoVillegas et al. 2008), but the precise function of these genes in rice has not yet been revealed.

\section{Photosynthesis-Related GO Terms}

Surprisingly, in Loto treated roots, 11 enriched GO-terms were related to photosynthesis (Fig. 5c and d), namely, "chloroplast thylakoid membrane" (GO:0009535), "photosynthesis, light harvesting" (GO:0009765), "plastoglobule" (GO:0010287), "chloroplast" (GO:0009507), "photosynthesis" (GO:0015979), "thylakoid" (GO:0009579), "chlorophyll binding" (GO:0016168), "chloroplast envelope" (GO:0009941), "plastid" (GO:0009536), "photosynthetic electron transport chain" (GO:0009767) and "stromule" (GO:0010319). Nevertheless, this result is consistent with other literature data. For example, in a transcriptomic analysis of leaves and roots of rice seedlings subjected to acute dehydration, many photosynthesis-related GO terms were enriched in roots under dehydration, including GO:0009579, GO:0009765 and GO:0016168 (Minh-Thu et al. 2013). Moreover, a transcriptome analysis revealed a down-regulation of genes encoding Sigma70-like family proteins in rice roots under osmotic stress (Ma et al. 2009). These proteins are involved in the control of chloroplast gene expression. The authors suggested that root genes 
may regulate enzymes and proteins that are related to photosynthesis.

\section{Cell Wall-Related Enriched GO Terms}

Major differences between the leaf samples of the 2 genotypes were found at $24 \mathrm{~h}$ of stress treatment, where Eurosis was mainly characterized by GO terms related to cell wall-related processes and Loto by GO terms related to peroxisomes and photoinhibition (Fig. 6b and d). In the cell wall-related GO terms that were enriched in Eurosis, several genes associated with lignin polymerization were present, including many peroxidases at $3 \mathrm{~h}$ of treatment and several laccases both at 3 and $24 \mathrm{~h}$ of treatment. Increased lignification has been observed in the leaf elongation zone of drought-stressed maize leaves (Vincent et al. 2005) and increased cell wall peroxidase activity has been implicated in the cessation of leaf growth under drought in darnel (Bacon et al. 1997). Moreover, several genes, which were listed in these GO terms, encode xyloglucan-modifying enzymes; this finding is consistent with the observation that more xyloglucan is synthesized during dehydration, promoting the strengthening of the cell wall through cross-linking and tightening (Moore et al. 2008). Similar results were reported in a recent transcriptome profiling study of the leaf elongation zone under drought that compared the gene expression between drought-tolerant and drought-sensitive rice varieties (Cal et al. 2013). Many of the differentially expressed genes were involved in secondary cell wall deposition, lignin polymerization, or coded for glycosyl hydrolases and xyloglucan endotransglucosylase/ hydrolases, suggesting that the two genotypes have alternative strategies for the regulation of leaf elongation under drought (Cal et al. 2013). Moreover, drought tolerance involves a restructuring of the cell wall that allows growth processes to occur at a lower water level; thus, cell wall adjustment under water stress is an important phenomenon in plant adaptation. These mechanisms, however, are complex and differ among plant species; many studies are still needed to understand how these processes influence plant stress tolerance (Moore et al. 2008).

\section{MapMan Pathway Analysis of $3 \mathrm{~h}$-Treated Roots}

Pathway-based analysis helps to further understand the biological function of genes. We used the MapMan package (http://mapman.gabipd.org/) as a tool to more thoroughly visualize the pathways involved in the osmotic stress response of the two genotypes. Because major differences in the stress response between the 2 cultivars were found in $3 \mathrm{~h}$-treated roots, all of the DEGs specifically modulated in $3 \mathrm{~h}$-treated root samples of Eurosis or Loto (3455 and 1410 genes in Eurosis and Loto, respectively; Table 3, Additional file 8: Table S8) were analysed using MapMan to identify differences in metabolic and regulatory pathways. The analysis showed that some pathways related to cell division, stress response, hormones, regulation, enzyme families and transport were differently regulated between the 2 cultivars, confirming the major results of the GO enrichment analysis (Fig. 7). In particular, the gene sets specific to each genotype included genes that encoded TFs, proteins involved in ethylene signalling and enzymes belonging to several families with a role in the plant stress response (e.g., cytochrome P450; Additional file 9: Table S9).

Among TF-encoding genes, approximately 40 genes were up-regulated only in Eurosis (Additional file 9: Table S9). Among them, LOC_Os02g22020 codes for a GARP TF, which regulates the response to osmotic stress in rice (Mito et al. 2011). This gene is the putative orthologue of HRS1, which acts as a negative regulator of ABA signalling during Arabidopsis seed germination. HRS1 may participate in the suppression of ABA signalling in the germinating embryo axis, which in turn promotes the germination of Arabidopsis seeds in either normal or salt stress environments (Wu et al. 2012). Very recently, it has been proposed that HRS1 represses primary root growth in response to phosphorus deficiency, integrating the signalling pathways related to phosphate and nitrate (Medici et al. 2015).

It is well known that MYB TFs have a prominent role in the response to drought in plant species (Baldoni et al. 2015). Among the five MYB genes (LOC_Os01g34060, LOC_Os01g65370, LOC_Os05g48010, LOC_Os06g43090 and LOC_Os08g33150) that were up-regulated only in Eurosis (Additional file 9: Table S9), the LOC_Os01g65370 gene is very close to OsMYB2P-1, which is associated with Pi starvation signalling and is involved in the regulation of root architecture (Dai et al. 2012). This TF may have a role in the root growth of Eurosis plants.

In addition to the originally identified role in defence signalling, WRKY TFs have a pivotal function in seed germination, flower development, senescence and the abiotic stress response (Tripathi et al. 2014). Three WRKY genes (LOC_Os01g09080/OsWRKY107, LOC_O s03g55080/OsWRKY3 and LOC_Os08g29660/OsWRK Y69) were up-regulated only in Eurosis (Additional file 9: Table S9). Consistently, OsWRKY69 expression is up-regulated in a drought tolerant cultivar (Douradão) compared to a sensitive cultivar (Primavera) under water shortage conditions, suggesting that its action in the signalling of the drought response may contribute to the tolerant phenotype of rice genotypes (Silveira et al. 2015). Interestingly, OsWRKY69 expression is regulated by ABL1, which is a rice basic region/leucine zipper motif TF involved in the ABA response, suggesting that OsWRKY69 may be involved in the signalling of the abiotic stress response (Yang et al. 2011). 


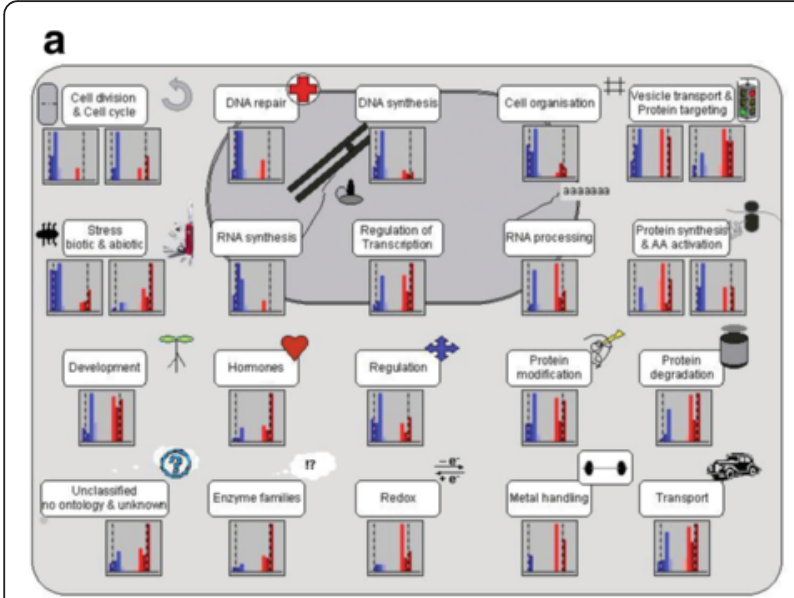

b

C

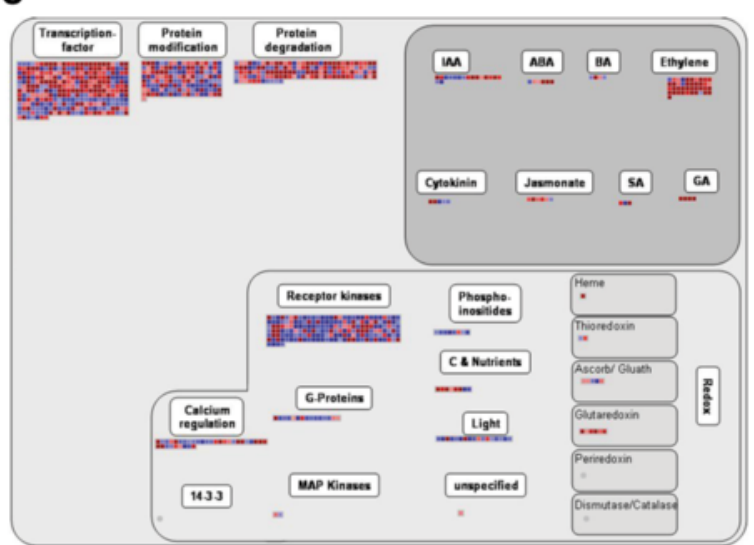

Eurosis

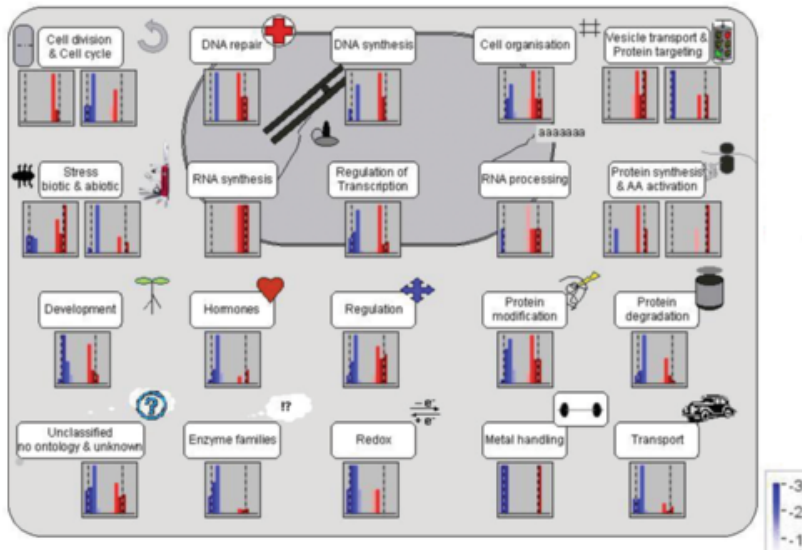

d

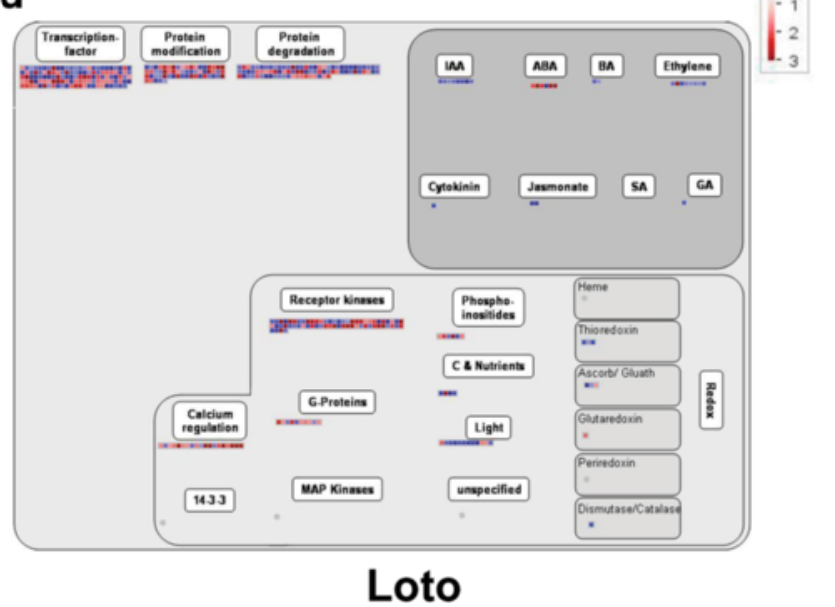

Fig. 7 MapMan analysis of genotype specific up- and down-regulated genes in 3 h-treated roots. MapMan analysis of Eurosis (left) or Loto (right) DEGs in 3 h-treated roots. $\mathbf{a}, \mathbf{b}$ Cell functions overview; $\mathbf{c}$, $\mathbf{d}$ Regulation overview. The colour scale indicates the degree of fold change expression values (light blue-blue, down-regulation; pink-red, up-regulation)

In higher plants, ethylene is synthesized via two enzyme-catalysed steps from S-adenosyl-L-methionine (SAM). The 1-aminocyclopropane-1-carboxylic acid (ACC) synthase (ACS) catalyses the cyclization of SAM to $\mathrm{ACC}$ and subsequently, the ACC oxidase (ACO) catalyses the oxidative conversion of ACC to ethylene (Yang and Hoffman 1984). ACS and ACO are encoded by medium and small-sized gene families, respectively, and their expression is differentially regulated by various developmental, environmental, and hormone signals (Bleecker and Kende 2000; Chen and McManus 2006; Binnie and McManus 2009). Here, MapMan analysis highlighted that some $A C O$ genes were differentially regulated between the two genotypes: LOC_Os03g64280 (ACO1) and LOC_Os08g30080 were up-regulated only in Eurosis, and LOC_Os06g37590 was down-regulated only in Eurosis, whereas LOC_Os03g63900 was down-regulated only in Loto (Additional file 9: Table S9). Literature data indicate that $A C O 1$ is involved in the accumulation of ethylene during submergence, and its activity may contribute to the initiation of adventitious root formation during submergence through the activation of epidermal cell death signalling (Steffens and Sauter 2009; Fukao and BaileySerres 2008).

Furthermore, MapMan analysis showed that 6 cytochrome P450 encoding genes (LOC_Os01g41810, LOC_Os02g47470, LOC_Os03g04660, LOC_Os05g25640, LOC_Os05g31740 and LOC_Os10g09110) were upregulated only in Eurosis, 2 cytochrome P450 encoding genes (LOC_Os01g12750 and LOC_Os11g18570) were upregulated only in Loto, and 2 cytochrome P450 encoding genes (LOC_Os01g72260 and LOC_Os10g12080) were down-regulated only in Loto (Additional file 9: Table S9). LOC_Os02g47470 and LOC_Os05g31740, which were upregulated only in Eurosis, seem to be involved in submergence tolerance (Kottapalli et al. 2007; Jung et al. 2010). In particular, LOC_Os02g47470 encodes the ABA 8'-hydroxylase (OsABA8ox1), which catalyses the major regulatory 
step of the predominant pathway for $\mathrm{ABA}$ inactivation via the conversion of ABA to phaseic acid (Kushiro et al. 2004). The involvement of OsABA80x1 in the drought response has been previously reported; the induction of OsABA8ox 1 under a water-deficient condition significantly suppressed the elevation of ABA levels (Yazawa et al. 2012). Ethylene partially contributes to the reduction of ABA concentration in submerged rice by activating OsABA80x1 (Saika et al. 2007); our observation about the up-regulation of the ACO1 gene in Eurosis suggests that in $3 \mathrm{~h}$-treated roots of this genotype a higher level of ethylene was present, leading to the up-regulation of OsABA8ox1. OsA$B A 80 \times 1$ is up-regulated after submergence in a rice genotype that is tolerant to a prolonged submergence (Jung et al. 2010). Since restriction of ROS production or removal of ROS during submergence and after desubmergence are critical factors for survival, the authors suggested that the activation of OsABA80x1 may contribute to reducing ROS, which are produced during ABA signalling (Kwak et al. 2003; Mittler and Blumwald 2015). A similar mechanism may occur in Eurosis and contribute to osmotic stress tolerance.

Moreover, two of the 10 cytP450 genes that were differentially expressed between Eurosis and Loto encode two enzymes involved in the phenylpropanoid pathway, namely, LOC_Os05g25640 and LOC_Os10g12080. LOC_Os05g25640, which was up-regulated only in Eurosis, codes for the cinnamic acid 4-hydroxylase $(\mathrm{C} 4 \mathrm{H})$, which transforms the cinnamic acid into Pcoumaric acid at the beginning of the phenylpropanoid pathway. LOC_Os10g12080, which is also named CYP98A15p (Liu et al. 2010), was down-regulated exclusively in Loto and encodes coumarate 3-hydroxylase $(\mathrm{C} 3 \mathrm{H})$, which transforms the P-coumaric acid into caffeic acid at the beginning of the lignin branch. An expression analysis conducted on two rice cultivars under oxidative stress showed a down-regulation of CYP98A15p in the more sensitive cultivar, which is consistent with our results (Liu et al. 2010). The authors hypothesized that the repression of lignin synthesis in the sensitive genotype may drive metabolic flux into flavonoids, which leads to a different metabolite flux between the tolerant and the sensitive genotypes (Liu et al. 2010). In a recent study, the expression level of genes involved in suberin and lignin production, including the $C 4 H$ gene, correlates well with the absolute suberin and lignin content in rice roots (Ranathunge et al. 2015). Our observation of the upregulation of $\mathrm{C} 4 \mathrm{H}$ only in Eurosis and the downregulation of $\mathrm{C} 3 \mathrm{H}$ only in Loto suggests the presence of a higher amount of suberin and lignin in Eurosis roots. Similarly to the $\mathrm{C} 4 \mathrm{H}$ gene, 4 above mentioned genes (e.g., LOC_Os07g01020 encoding a putative
SOR/SNZ family protein; LOC_OsOs03g06510 encoding a KRP; LOC_Os02g22020 encoding a GARP TF and LOC_Os01g65370 encoding a MYB TF) were differentially regulated between the analysed rice genotypes and were previously reported to be involved in root growth and development. These genes may have a role in the root growth and contribute to the tolerant response of Eurosis plants.

Recently, a transcriptomic analysis on Arabidopsis found that salt acclimation is mediated by DEGs involved in cell wall biosynthesis, osmoregulation and oxidative stress, by TF-encoding DEGs and by DEGs participating in the synthesis of lignin and ethylene biosynthesis (Shen et al. 2014). Here, we showed that similar categories of genes characterized the osmotic stress response of a tolerant rice genotype, suggesting that the tolerant phenotype of Eurosis to osmotic stress may be characterized by a similar mechanism involving the root system in particular.

\section{Conclusions}

This study provided a comprehensive overview of the transcriptome changes that specifically occur in roots and leaves of two japonica rice genotypes, which were characterized by a contrasting phenotype in response to osmotic stress. RNA-Seq data highlighted that the tolerant genotype Eurosis and the sensitive genotype Loto mainly differed in their early response to osmotic stress in roots. A schematic representation of some mechanisms putatively involved in the higher tolerance to osmotic stress of Eurosis is shown in Fig. 8. Differential response included a prompt regulation of genes related to chromatin, cytoskeleton and transmembrane transporters in the tolerant genotype. Moreover, the differential regulation of TFs (Fig. 8a) and hormone-mediate signalling was observed. In particular, some of the hormone-related DEGs may reduce ROS content in the roots of the tolerant genotype (Fig. 8b). Furthermore, genes involved in the biosynthesis of lignin in the roots may determine the tolerant vs. sensitive response (Fig. 8c). The function of these genes in the water stress response and the physiological mechanisms in which they are involved still have to be elucidated. Nonetheless, some of the genes identified in this work may be important players in the tolerance response and could represent good candidate genes for improvement of the rice germplasm.

\section{Methods}

Plant Material, Growth Conditions and Osmotic Stress Treatment

Seventeen Italian rice cultivars (O. sativa L. ssp japonica) were subjected to PEG-mediated osmotic stress, namely 


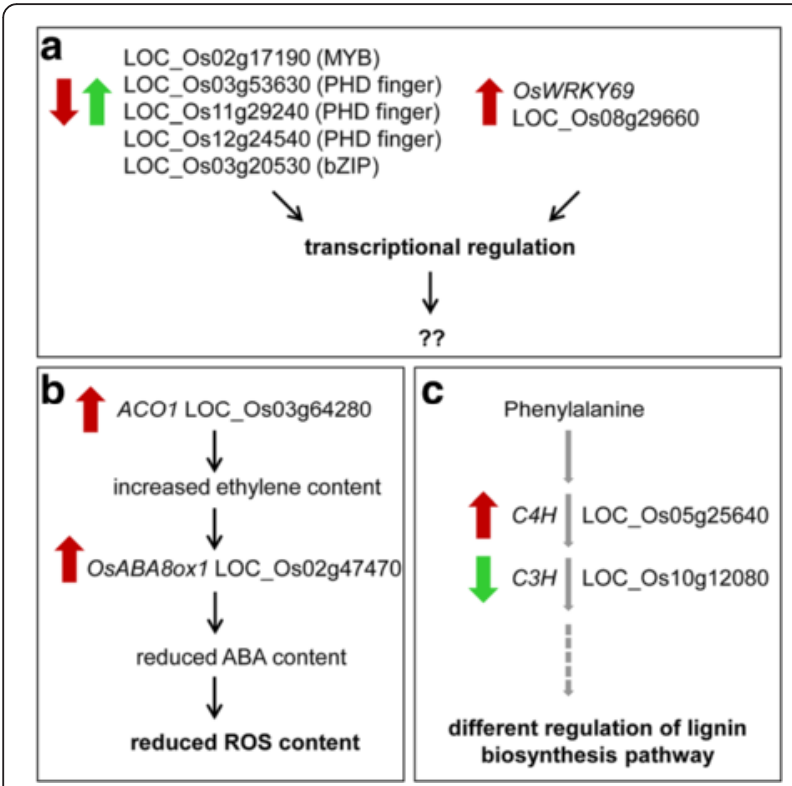

Fig. 8 Schematic representation of some root mechanisms putatively involved in osmotic stress tolerance of Eurosis. Red and green arrows indicate gene regulation under osmotic treatment in Eurosis and Loto, respectively. Grey arrows indicate enzymatic steps in the lignin biosynthetic pathway

Arborio, Asia, Augusto, Baldo, Carnaroli, Eurosis, Gigante Vercelli, Gladio, Koral, Loto, Maratelli, Salvo, SISR215, Thaibonnet, Venere, Vialone Nano and Volano. The rice seeds were kindly provided by the Rice Research Unit (CREA-RIS, Vercelli, Italy).

All of the hydroponic experiments were performed in a controlled growth room at $28{ }^{\circ} \mathrm{C} / 23{ }^{\circ} \mathrm{C}$ under a $14 \mathrm{~h}$ light/10 h dark photoperiod with a light intensity of $200 \mu \mathrm{mol} \mathrm{m} \mathrm{m}^{-2} \mathrm{~s}^{-1}$ and $60 \%$ relative humidity. Plant growth and osmotic stress treatment were performed as described in Baldoni et al. (2013). After 4 days of germination in Petri dishes, seedlings were grown in hydroponic culture with standard Yoshida nutrient solution (Duchefa Biochemistry, Harlem, The Netherlands). After 20 days of growth (third-leaf stage), half of the plants were transferred to a nutrient solution with $20 \%$ (w/v) PEG6000 (Duchefa Biochemistry, Harlem, The Netherlands) at $11.00 \mathrm{am}$ (3 $\mathrm{h}$ after the onset of illumination), to impose an osmotic stress treatment. For RNA purification, leaves (the second and third leaf) and roots from control or treated plants were collected separately in pools of 6 plants after $3(14: 00 \mathrm{pm})$ and $24 \mathrm{~h}(11: 00 \mathrm{am})$ of PEG treatment.

\section{Physiological Measurements}

Leaf RWC was measured after 0, 3, 24 and 48 h of PEG treatment, as described in Baldoni et al. (2013). Leaf EL was measured after $0,3,24$ and 48 h of PEG treatment to evaluate cell membrane stability following the method of Shou et al. (2004) with minor modifications. For each sample, 6 leaves from 3 plants (2 leaves per plant) were collected, rinsed with deionized water and cut into 7$\mathrm{mm}$ pieces. Leaf discs were incubated in tubes with $20 \mathrm{ml}$ of deionized water, and the tubes were shaken overnight in a slanted position. The initial conductivity of the incubation $(\mathrm{Ci})$ was measured using a conductivity meter (Thermo Orion star Plus, Beverly MA) to estimate the amount of ions released from cells under normal conditions or PEG treatment. Leaf tissue in the incubation solution was then boiled at $100{ }^{\circ} \mathrm{C}$ for $30 \mathrm{~min}$ to completely disrupt the cell structure. The conductivity of the boiled solution $(\mathrm{Cmax})$ was determined after cooling at room temperature. These 2 measurements were carried out individually for all of the samples from both the control and stressed plants. The percentage of EL was calculated by dividing the $C i$ by the $C \max$. For each genotype and condition, 7 biological replicates were measured.

For each sampling time, RWC and EL data were subjected to a one-way analysis of variance (ANOVA) after angular transformation of raw data. Comparison among means was performed using a Tukey's test. Significant differences were accepted at $p<0.01$.

\section{RNA Isolation and Quantitative RT-PCR Analysis}

Total RNA was extracted from the leaves and roots using the $\mathrm{TRIzol}^{\odot}$ RNA Purification Kit (Invitrogen, Carlsbad, CA) following the manufacturer's instructions. RNA purity was checked spectrophotometrically (Nanodrop ND-1000 Spectrophotometer; Celbio, Italy), and only samples with a $260 / 280 \mathrm{~nm}$ ratio of absorbance comprised between 1.7 and 2.1 were further used. The integrity of the RNA was verified using the RNA 6000 Nano Labchip Kit on an Agilent 2100 Bioanalyzer (Agilent Technologies, USA), following the manufacturer's protocol. Only samples with a $28 \mathrm{~S} / 18 \mathrm{~S}$ ratio $\geq 2$ were used for further experiments.

The cDNA synthesis and quantitative RT-PCR was performed as described in Baldoni et al. (2013).

\section{Illumina RNA-Sequencing}

Four micrograms of total RNA was subjected to library preparation using the TruSeq mRNA Sample Prep Kit from Illumina (Illumina, Inc., CA, USA) following the manufacturer's instructions. Library concentration and size were assayed on a 2100 Bioanalyzer (Agilent). Single-end sequencing (50 bases) was conducted on an Illumina HiSeq2000 with samples run in 6-plex. Illumina sequencing was performed at IGA Technology Services Srl Service Provider (Udine, Italy). 


\section{Bioinformatic Methods}

\section{Mapping of Illumina Reads}

A preliminary read trimming (from 50 to 43 bases) step was performed to discard poor quality bases that were abundantly detected in the 3 ' terminal region. The resulting trimmed reads were checked for contaminants, and low quality bases and contaminants were removed using the cutadapt software (Martin 2011). The spliced read mapper TopHat version 1.4.1 (Trapnell et al. 2012) was used to map reads to rice $O$. sativa Nipponbare genome (MSU release 6.16). A minimum and maximum intron length of 40 and 50,000 were used, respectively. Read counts were collected with HTSeq version 0.5.3 (Anders et al. 2014) in the single end and 'union' mode using $O$. sativa MSU $6.16 \mathrm{gtf}$ file as performed for the ensemble plant repository.

\section{Differentially Regulated Gene Calling}

The DESeq Bioconductor package version 1.10.1 (Anders and Huber 2010) was used to call DEGs under $\mathrm{R}$ release 2.15.2. The cut-off for considering a gene as expressed was set to 0.1 RPKM (Reads per Kilobase per Million). Two distinct DESeq countSet object instances were created for Eurosis and Loto. DESeq parameters for dispersion estimation were the method 'pooled' and sharingMode 'Maximum'. For DEG calling, the FDR threshold was set to 0.001 and the fold change threshold to 3 .

\section{Gene Ontology Enrichment Analyses}

For goseq analyses, gene lengths were retrieved with BiomaRt queries (O. sativa MSU 6.16) out of rice Nipponbare $\mathrm{cDNA}$, and the median length for each rice locus was obtained by parsing with $\mathrm{R}$ custom scripts. GO annotations were obtained using BiomaRt queries (O. sativa MSU 6.16). An FDR cut-off of 0.05 was used for $\mathrm{GO}$ enrichments.

\section{Miscellaneous Bioinformatic Techniques}

Heatmaps of the expression and various graphical outputs were generated with custom $\mathrm{R}$ scripts based on Bioconductor packages (Gentleman et al. 2004). Sample clustering was performed after data transformation via variance stabilizing transformation function (DESeq package; Anders and Huber 2010), and heatmaps were generated via the heatmap.2 function as available in the 'gplots' Bioconductor package. MapMan figures were generated upon binning of DEG sequences to MapMan bins by the Mercator application (Lohse et al. 2014). Unless otherwise stated, further graphical outputs were generated with custom $\mathrm{R}$ and Python scripts.

\section{Additional Files}

Additional file 1: Table S1. Read number and alignment statistics. Passed-
filter reads refer to preliminary Illumina inbuilt read scoring. (PDF $185 \mathrm{~kb}$ )

Additional file 2: Table S2. Pearson correlation coefficients of samples. (XLSX 25 kb)

Additional file 3: Table S3. Comparisons of RNA-Seq and GRT-PCR data. Comparisons of transcript fold changes as detected by RNA-Seq and GRT-PCR expression analyses for 10 selected genes in all of the experimental conditions. Comparisons of the differences between the means of treated and untreated samples of qRT-PCR data were performed using Student's $t$-tests ( $p$-value $\leq 0.05$ except for the data marked with ${ }^{n s}$ ). OsCAT-A: Catalase isozyme A; OsZCO: Zeaxanthin cleavage oxygenase. (PDF $291 \mathrm{~kb}$ )

Additional file 4: Table S4. List of DEGs in all of the analysed samples. (XLSX 3592 kb)

Additional file 5: Table S5. List of DEGs showing contrasting regulation between Eurosis and Loto samples. (XLSX $12 \mathrm{~kb}$ )

Additional file 6: Table S6. List of common GO terms. List of GO terms common in all of the tissues and treatments, in all of the root samples or in all of the leaf samples. (XLSX $21 \mathrm{~kb}$ )

Additional file 7: Table S7. List of enriched GO terms for the contrasts with accompanying enrichment $p$-values as resulting from goseq analysis. (XLSX 62 kb)

Additional file 8: Table S8. List of DEGs specifically modulated in 3 htreated root samples of Eurosis or Loto. (XLSX 184 kb)

Additional file 9: Table S9. List of DEGs belonging to MapMan categories "Ethylene", "Transcription Factor", "Enzyme families Cytochrome P450." (XLSX 88 kb)

\section{Abbreviations}

ABA: abscisic acid; ABC: ATP-binding cassette; ACC: 1-aminocyclopropane-1carboxylic acid; ACO: ACC oxidase; ACS: ACC synthase; BP: biological process; $\mathrm{C} 3 \mathrm{H}$ : coumarate 3-hydroxylase; $\mathrm{C} 4 \mathrm{H}$ : cinnamic acid 4-hydroxylase; CC: cellular component; CI: initial conductivity; Cmax: absolute conductivity; DEG: differentially expressed gene; EL: electrolyte leakage; FDR: false discovery rate; GO: gene ontology; KRP: Kip-related protein; MATE: multidrug and toxic compound extrusion; MF: molecular function; ns-Hb: non-symbiotic haemoglobin; PEG: polyethylene glycol; RPKM: reads per kilobase per million; RWC: relative water content; SAM: S-adenosyl-L-methionine; TF: transcription factor.

\section{Acknowledgments}

This work was supported by Progetto AGER, grant n²010-2369 - Integrated Genetic And Genomic Approaches For New Italian Rice Breeding Strategies (RISINNOVA).

\section{Authors' contributions}

E.B. and A.G. conceived and designed the research. E.B., F.L. and M.M. performed the stress treatments and the physiological measurements. E.B. performed the RNA isolation and the quantitative RT-PCR analysis. P.B. performed the bioinformatic analysis. E.B. and P.B. analyzed the data. E.B. and A.G. wrote the manuscript. All authors read and approved the final manuscript.

\section{Competing interests}

The authors declare that they have no competing interests.

\section{Author details}

${ }^{1}$ Institute of Agricultural Biology and Biotechnology - National Research Council, via Bassini 15, 20133 Milan, Italy. ${ }^{2}$ Dipartimento di Scienze Agrarie e Ambientali - Produzione, Territorio, Agroenergia, Università degli Studi di Milano, Via Celoria 2, 20133 Milan, Italy. ${ }^{3}$ Consiglio per la ricerca in agricoltura e I'analisi dell'economia agraria, Genomics Research Centre, Fiorenzuola d'Arda, Piacenza, Italy.

Received: 13 January 2016 Accepted: 14 May 2016 Published online: 23 May 2016 


\section{References}

Anders S, Huber W (2010) Differential expression analysis for sequence count data. Genome Biol 11:R106. doi:10.1186/gb-2010-11-10-r106

Anders S, Pyl PT, Huber W (2014) HTSeq - A Python framework to work with high-throughput sequencing data. Bioinformatics 2014:1-4. doi:10.1093/ bioinformatics/btu638

Bacon MA, Thompson DS, Davies WJ (1997) Can cell wall peroxidase activity explain the leaf growth response of Lolium temulentum L. during drought? J Exp Bot 48:2075-2085. doi:10.1093/jxb/48.12.2075

Baldoni E, Mattana M, Locatelli F, Consonni R, Cagliani LR, Picchi V, Abbruscato P Genga A (2013) Analysis of transcript and metabolite levels in Italian rice (Oryza sativa L.) cultivars subjected to osmotic stress or benzothiadiazole treatment Plant Physiol Biochem 70:492-503. doi:10.1016/j.plaphy.2013.06.016

Baldoni E, Genga A, Cominelli E (2015) Plant MYB transcription factors: their role in drought response mechanisms. Int J Mol Sci 16:15811-15851. doi:10.3390/ ijms160715811

Bates BC, Kundzewicz ZW, Wu S, Palutikof JP (eds) (2008) Climate change and water. Technical paper of the intergovernmental panel on climate change. IPCC Secretariat, Geneva, p 210

Binnie IE, McManus MT (2009) Characterization of the 1-aminocyclopropane-1carboxylic acid (ACC) oxidase multigene family of Malus domestica Borkh. Phytochemistry 70:348-360. doi:10.1016/j.phytochem.2009.01.002

Bleecker AB, Kende H (2000) Ethylene: a gaseous signal molecule in plants. Annu Rev Cell Dev Biol. 1-18. doi:10.1146/annurev.cellbio.16.1.1

Bouman BAM, Humphreys E, Tuong TP, Barker R, Sparks DL (2007) Rice and water. Adv Agron 92:187-237. doi:10.1016/S0065-2113(04)92004-4

Cal AJ, Liu DC, Mauleon R, Hsing YIC, Serraj R (2013) Transcriptome profiling of leaf elongation zone under drought in contrasting rice cultivars. PLoS One 8(1):e54537. doi:10.1371/journal.pone.0054537

Chaves MM, Flexas J, Pinheiro C (2009) Photosynthesis under drought and salt stress: regulation mechanisms from whole plant to cell. Ann Bot London 103 551-560. doi:10.1093/aob/mcn125

Chen BCM, McManus MT (2006) Expression of 1-aminocyclopropane-1carboxylate (ACC) oxidase genes during the development of vegetative tissues in white clover (Trifolium repens L.) is regulated by ontological cues. Plant Mol Biol 60:451-467. doi:10.1007/s11103-005-4813-3

Chen W, Gao YQ, Xie WB, Gong L, Lu K, Wang WS, Li Y, Liu XQ, Zhang HY, Dong HX, Zhang W, Zhang LJ, Yu SB, Wang GW, Lian XM, Luo J (2014) Genome-wide association analyses provide genetic and biochemical insights into natural variation in rice metabolism. Nat Genet 46:714-721. doi:10.1038/ng.3007

Claeys H, Inze D (2013) The agony of choice: how plants balance growth and survival under water-limiting conditions. Plant Physiol 162:1768-1779, http:// dx.doi.org/10.1104/pp.113.220921

Dai XY, Wang YY, Yang A, Zhang WH (2012) OsMYB2P-1, an R2R3 MYB transcription factor, is involved in the regulation of phosphate-starvation responses and root architecture in rice. Plant Physiol 159:169-183, http://dx. doi.org/10.1104/pp.112.194217

de Souza Filho GA, Ferreira BS, Dias JM, Queiroz KS, Branco AT, Bressan-Smith RE, Oliveira JG, Garcia AB (2003) Accumulation of SALT protein in rice plants as a response to environmental stresses. Plant Sci 164:623-628. doi:10.1016/ S0168-9452(03)00014-1

Degenkolbe T, Do PT, Zuther E, Repsilber D, Walther D, Hincha DK, Kohl KI (2009) Expression profiling of rice cultivars differing in their tolerance to long-term drought stress. Plant Mol Biol 69:133-153. doi:10.1007/s11103-008-9412-7

Degenkolbe T, Do PT, Kopka J, Zuther E, Hincha DK, Kohl KI (2013) Identification of drought tolerance markers in a diverse population of rice cultivars by expression and metabolite profiling. PLoS One 8(5):e63637. doi:10.1371/ journal.pone.0063637

Fujita Y, Fujita M, Shinozaki K, Yamaguchi-Shinozaki K (2011) ABA-mediated transcriptional regulation in response to osmotic stress in plants. J Plant Res 124:509-525. doi:10.1007/s10265-011-0412-3

Fukao T, Bailey-Serres J (2008) Ethylene - A key regulator of submergence responses in rice. Plant Sci 175:43-51. doi:10.1016/j.plantsci.2007.12.002

Garrocho-Villegas V, Bustos-Rivera G, Gough J, Vinogradov SN, Arredondo-Peter R (2008) Expression and in silico structural analysis of a rice (Oryza sativa) hemoglobin 5. Plant Physiol Biochem 46:855-859. doi:10.1016/j.plaphy.2008.05.004

Gentleman RC, Carey VJ, Bates DM, Bolstad B, Dettling M, Dudoit S, Ellis B, Gautier L, Ge YC, Gentry J, Hornik K, Hothorn T, Huber W, lacus S, Irizarry R, Leisch F, Li C, Maechler M, Rossini AJ, Sawitzki G, Smith C, Smyth G, Tierney L, Yang JYH, Zhang JH (2004) Bioconductor: open software development for computational biology and bioinformatics. Genome Biol 5:R80. doi:10.1186/gb-2004-5-10-r80
Guan C, Ji J, Guan W, Li X, Jin C, Li J, Wang Y, Wang G (2014) LCKRP, a cyclindependent kinase inhibitor from Lycium chinense, is involved in an ABAdependent drought stress-signaling pathway. Plant Soil 382:43-59. doi:10. 1007/s11104-014-2134-5

Guimaraes PM, Brasileiro ACM, Morgante CV, Martins ACQ, Pappas G, Silva OB, Togawa R, Leal-Bertioli SCM, Araujo ACG, Moretzsohn MC, Bertioli DJ (2012) Global transcriptome analysis of two wild relatives of peanut under drought and fungi infection. BMC Genomics 13:387. doi:10.1186/1471-2164-13-387

Hadiarto T, Tran LSP (2011) Progress studies of drought-responsive genes in rice. Plant Cell Rep 30:297-310. doi:10.1007/s00299-010-0956-z

Himanen K, Boucheron E, Vanneste S, de Almeida Engler J, Inzé D, Beeckman T (2002) Auxin-mediated cell cycle activation during early lateral root initiation. Plant Cell 14:2339-2351, http://dx.doi.org/10.1105/tpc.004960

Hu YF, Zhu N, Wang XM, Yi QP, Zhu DY, Lai Y, Zhao Y (2013) Analysis of rice Snf2 family proteins and their potential roles in epigenetic regulation. Plant Physiol Biochem 70:33-42. doi:10.1016/j.plaphy.2013.05.001

Humphrey TV, Haasen KE, Aldea-Brydges MG, Sun H, Zayed Y, Indriolo E, Goring DR (2015) PERK-KIPK-KCBP signalling negatively regulates root growth in Arabidopsis thaliana. J Exp Bot 66:71-83. doi:10.1093/jxb/eru390

Jarzyniak KM, Jasinski M (2014) Membrane transporters and drought resistance a complex issue. Front Plant Sci 5:687. doi:10.3389/fpls.2014.00687

Jeong JS, Kim YS, Redillas MCFR, Jang G, Jung H, Bang SW, Choi YD, Ha SH, Reuzeau C, Kim JK (2013) OsNAC5 overexpression enlarges root diameter in rice plants leading to enhanced drought tolerance and increased grain yield in the field. Plant Biotechnol J 11:101-114. doi:10.1111/pbi.12011

Jung KH, Seo YS, Walia H, Cao PJ, Fukao T, Canlas PE, Amonpant F, Bailey-Serres J, Ronald PC (2010) The submergence tolerance regulator Sub1A mediates stress-responsive expression of AP2/ERF transcription factors. Plant Physiol 152:1674-1692, http://dx.doi.org/10.1104/pp.109.152157

Karim S, Lundh D, Holmstrom KO, Mandal A, Pirhonen M (2005) Structural and functional characterization of AtPTR3, a stress-induced peptide transporter of Arabidopsis. J Mol Model 11:226-236. doi:10.1007/s00894-005-0257-6

Karim S, Holmstrom KO, Mandal A, Dahl P, Hohmann S, Brader G, Palva ET, Pirhonen M (2007) AtPTR3, a wound-induced peptide transporter needed for defence against virulent bacterial pathogens in Arabidopsis. Planta 225:14311445. doi:10.1007/s00425-006-0451-5

Kim JM, Sasaki T, Ueda M, Sako K, Seki M (2015) Chromatin changes in response to drought, salinity, heat, and cold stresses in plants. Front Plant Sci 6:114. doi:10.3389/fpls.2015.00114

Kottapalli KR, Satoh K, Rakwal R, Shibato J, Doi K, Nagata T, Kikuchi S (2007) Combining in silico mapping and arraying: an approach to identifying common candidate genes for submergence tolerance and resistance to bacterial leaf blight in rice. Mol Cells 24:394-408

Krasensky J, Jonak C (2012) Drought, salt, and temperature stress-induced metabolic rearrangements and regulatory networks. J Exp Bot 63:1593-1608. doi:10.1093/jxb/err460

Kumar A, Bernier J, Verulkar S, Lafitte HR, Atlin GN (2008) Breeding for drought tolerance: direct selection for yield, response to selection and use of drought-tolerant donors in upland and lowland-adapted populations. Field Crop Res 107:221-231. doi:10.1016/j.fcr.2008.02.007

Kushiro T, Okamoto M, Nakabayashi K, Yamagishi K, Kitamura S, Asami T, Hirai N, Koshiba T, Kamiya Y, Nambara E (2004) The Arabidopsis cytochrome P450 CYP707A encodes ABA 8'-hydroxylases: key enzymes in ABA catabolism. Embo J 23:1647-1656. doi:10.1038/sj.emboj.7600121

Kwak JM, Mori IC, Pei ZM, Leonhardt N, Torres MA, Dangl JL, Bloom RE, Bodde S, Jones JDG, Schroeder JI (2003) NADPH oxidase AtrbohD and AtrbohF genes function in ROS-dependent ABA signaling in Arabidopsis. Embo J 22:26232633. doi:10.1093/emboj/cdg277

Lampayan RM, Rejesus RM, Singleton GR, Bouman BAM (2015) Adoption and economics of alternate wetting and drying water management for irrigated lowland rice. Field Crop Res 170:95-108. doi:10.1016/j.fcr.2014.10.013

Lenka SK, Katiyar A, Chinnusamy V, Bansal KC (2011) Comparative analysis of drought-responsive transcriptome in Indica rice genotypes with contrasting drought tolerance. Plant Biotechnol J 9:315-327. doi:10.1111/j.1467-7652. 2010.00560.x

Li XY, Wang C, Nie PP, Lu XW, Wang M, Liu W, Yao J, Liu YG, Zhang QY (2011) Characterization and expression analysis of the SNF2 family genes in response to phytohormones and abiotic stresses in rice. Biol Plant 55:625633. doi:10.1007/s10535-011-0160-1

Li J, Xu YY, Chong K (2012) The novel functions of kinesin motor proteins in plants. Protoplasma 249:95-100. doi:10.1007/s00709-011-0357-3 
Liu FX, Xu WY, Wei Q, Zhang ZH, Xing Z, Tan LB, Di C, Yao DX, Wang CC, Tan YJ, Yan H, Ling Y, Sun CQ, Xue YB, Su Z (2010) Gene expression profiles deciphering rice phenotypic variation between Nipponbare (japonica) and 93-11 (indica) during oxidative stress. PLoS One 5(1):e8632. doi:10.1371/ journal.pone.0008632

Lohse M, Nagel A, Herter T, May P, Schroda M, Zrenner R, Tohge T, Fernie AR, Stitt M, Usadel B (2014) Mercator: a fast and simple web server for genome scale functional annotation of plant sequence data. Plant Cell Environ 37: 1250-1258. doi:10.1111/pce.12231

Ma TC, Chen RJ, Yu RR, Zeng HL, Zhang DP (2009) Differential global genomic changes in rice root in response to low-, middle-, and high-osmotic stresses. Acta Physiol Plant 31:773-785. doi:10.1007/s11738-009-0291-6

Martin M (2011) Cutadapt removes adapter sequences from high-throughput sequencing reads. EMBnetjournal 17:10-12, http//dx.doi.org/10.14806/ej.17.1.200

Matsuda S, Funabiki A, Furukawa K, Komori N, Koike M, Tokuji Y, Takamure I, Kato K (2012) Genome-wide analysis and expression profiling of half-size ABC protein subgroup $\mathrm{G}$ in rice in response to abiotic stress and phytohormone treatments. Mol Genet Genomics 287:819-835. doi:10.1007/s00438-012-0719-3

Medici A, Marshall-Colon A, Ronzier E, Szponarski W, Wang RC, Gojon A, Crawford NM, Ruffel S, Coruzzi GM, Krouk G (2015) AtNIGT1/HRS1 integrates nitrate and phosphate signals at the Arabidopsis root tip. Nat Commun 6:6274. doi: 10.1038/ncomms7274

Minh-Thu PT, Hwang DJ, Jeon JS, Nahm BH, Kim YK (2013) Transcriptome analysis of leaf and root of rice seedling to acute dehydration. Rice 6:38. doi:10.1186/ 1939-8433-6-38

Mito T, Seki M, Shinozaki K, Ohme-Takagi M, Matsui K (2011) Generation of chimeric repressors that confer salt tolerance in Arabidopsis and rice. Plant Biotechnol J 9:736-746. doi:10.1111/j.1467-7652.2010.00578.x

Mittler R, Blumwald E (2015) The roles of ROS and ABA in systemic acquired acclimation. Plant Cell 27:64-70, http://dx.doi.org/10.1105/tpc.114.133090

Moons A (2008) Transcriptional profiling of the PDR gene family in rice roots in response to plant growth regulators, redox perturbations and weak organic acid stresses. Planta 229:53-71. doi:10.1007/s00425-008-0810-5

Moore JP, Vicre-Gibouin M, Farrant JM, Driouich A (2008) Adaptations of higher plant cell walls to water loss: drought vs desiccation. Physiol Plant 134:237245. doi:10.1111/j.1399-3054.2008.01134.x

Moumeni A, Satoh K, Kondoh H, Asano T, Hosaka A, Venuprasad R, Serraj R, Kumar A, Leung H, Kikuchi S (2011) Comparative analysis of root transcriptome profiles of two pairs of drought-tolerant and susceptible rice near-isogenic lines under different drought stress. BMC Plant Biol 11:174. doi: 10.1186/1471-2229-11-174

Moumeni A, Satoh K, Venuprasad R, Serraj R, Kumar A, Leung H, Kikuchi S (2015) Transcriptional profiling of the leaves of near-isogenic rice lines with contrasting drought tolerance at the reproductive stage in response to water deficit. BMC Genomics 16:1110. doi:10.1186/s12864-015-2335-1

Nakashima K, Yamaguchi-Shinozaki K, Shinozaki K (2014) The transcriptional regulatory network in the drought response and its crosstalk in abiotic stress responses including drought, cold, and heat. Front Plant Sci 5:170. doi:10. 3389/fpls.2014.00170

Nguyen VNT, Moon S, Jung KH (2014) Genome-wide expression analysis of rice ABC transporter family across spatio-temporal samples and in response to abiotic stresses. J Plant Physiol 171:1276-1288. doi:10.1016/j.jplph.2014.05.006

Oshlack A, Wakefield MJ (2009) Transcript length bias in RNA-seq data confounds systems biology. Biol Direct 4:14. doi:10.1186/1745-6150-4-14

Perruc E, Kinoshita N, Lopez-Molina L (2007) The role of chromatin-remodeling factor PKL in balancing osmotic stress responses during Arabidopsis seed germination. Plant J 52:927-936. doi:10.1111/j.1365-313X.2007.03288.x

Qin F, Shinozaki K, Yamaguchi-Shinozaki K (2011) Achievements and challenges in understanding plant abiotic stress responses and tolerance. Plant Cell Physiol 52:1569-1582. doi:10.1093/pcp/pcr106

Ranathunge K, Schreiber L, Bi YM, Rothstein SJ (2015) Ammonium-induced architectural and anatomical changes with altered suberin and lignin levels significantly change water and solute permeabilities of rice (Oryza sativa L.) roots. Planta. doi:10.1007/s00425-015-2406-1

Richards RA (1996) Defining selection criteria to improve yield under drought. Plant Growth Regul 20:157-166. doi:10.1007/BF00024012

Robinson MD, Oshlack A (2010) A scaling normalization method for differential expression analysis of RNA-seq data. Genome Biol 11:R25. doi:10.1186/gb2010-11-3-r25

Rüdiger H, Gabius HJ (2001) Plant lectins: occurrence, biochemistry, functions and applications. Glycoconjugate J 18:589-613
Saha J, Sengupta A, Gupta K, Gupta B (2015) Molecular phylogenetic study and expression analysis of ATP-binding cassette transporter gene family in Oryza sativa in response to salt stress. Comput Biol Chem 54:18-32. doi:10.1016/j. compbiolchem.2014.11.005

Saier MH, Tran CV, Barabote RD (2006) TCDB: the Transporter Classification Database for membrane transport protein analyses and information. Nucleic Acids Res 34:D181-D186. doi:10.1093/nar/gkj001

Saika H, Okamoto M, Kushiro T, Shinoda S, Jikumaru Y, Fujimoto M, Miyoshi K, Arikawa T, Arimura SI, Kamiya Y, Tsutsumi N, Nambara E, Nakazono M (2007) Ethylene promotes submergence-induced expression of OSABA80Xl, a gene that encodes ABA 8'-hydroxylase in rice. Plant Cell Physiol 48:287-298. doi:10. 1093/pcp/pcm003

Shen XY, Wang ZL, Song XF, Xu JJ, Jiang CY, Zhao YX, Ma CL, Zhang H (2014) Transcriptomic profiling revealed an important role of cell wall remodeling and ethylene signaling pathway during salt acclimation in Arabidopsis. Plant Mol Biol 86:303-317. doi:10.1007/s11103-014-0230-9

Shinozaki K, Yamaguchi-Shinozaki K (2007) Gene networks involved in drought stress response and tolerance. J Exp Bot 58:221-227. doi:10.1093/jxb/erl164

Shou HX, Bordallo P, Fan JB, Yeakley JM, Bibikova M, Sheen J, Wang K (2004) Expression of an active tobacco mitogen-activated protein kinase kinase kinase enhances freezing tolerance in transgenic maize. Proc Natl Acad Sci U S A 101:3298-3303. doi:10.1073/pnas.0308095100

Shu LB, Lou QJ, Ma CF, Ding W, Zhou J, Wu JH, Feng FJ, Lu X, Luo LJ, Xu GW, Mei HW (2011) Genetic, proteomic and metabolic analysis of the regulation of energy storage in rice seedlings in response to drought. Proteomics 11: 4122-4138. doi:10.1002/pmic.201000485

Silveira RDD, Abreu FRM, Mamidi S, McClean PE, Vianello RP, Lanna AC, Carneiro NP, Brondani C (2015) Expression of drought tolerance genes in tropical upland rice cultivars (Oryza sativa). Genet Mol Res 14(3):8181-8200. doi:10. 4238/2015.July.27.6

Steffens B, Sauter M (2009) Epidermal cell death in rice is confined to cells with a distinct molecular identity and is mediated by ethylene and $\mathrm{H}_{2} \mathrm{O}_{2}$ through an autoamplified signal pathway. Plant Cell 21:184-196, http://dx.doi.org/10. 1105/tpc.108.061887

Suzuki S, Yamamura M, Hattori T, Nakatsubo T, Umezawa T (2007) The subunit composition of hinokiresinol synthase controls geometrical selectivity in norlignan formation. Proc Natl Acad Sci U S A 104:21008-21013. doi:10.1073/ pnas.0710357105

Takanashi K, Shitan N, Yazaki K (2014) The multidrug and toxic compound extrusion (MATE) family in plants. Plant Biotechnol 31:417-430. doi:10.5511/ plantbiotechnology.14.0904a

Trapnell C, Roberts A, Goff L, Pertea G, Kim D, Kelley DR, Pimentel H, Salzberg SL, Rinn JL, Pachter L (2012) Differential gene and transcript expression analysis of RNA-seq experiments with TopHat and Cufflinks. Nat Protoc 7:562-578. doi:10.1038/nprot.2012.016

Tripathi P, Rabara RC, Rushton PJ (2014) A systems biology perspective on the role of WRKY transcription factors in drought responses in plants. Planta 239: 255-266. doi:10.1007/s00425-013-1985-y

Tuteja N, Sahoo RK, Garg B, Tuteja R (2013) OsSUV3 dual helicase functions in salinity stress tolerance by maintaining photosynthesis and antioxidant machinery in rice (Oryza sativa L. cv. IR64). Plant J 76:115-127. doi:10.1111/tpj.12277

Utsumi Y, Tanaka M, Morosawa T, Kurotani A, Yoshida T, Mochida K, Matsui A, Umemura Y, Ishitani M, Shinozaki K, Sakurai T, Seki M (2012) Transcriptome analysis using a high-density oligomicroarray under drought stress in various genotypes of cassava: an important tropical crop. DNA Res 19:335-345. doi: 10.1093/dnares/dss016

Valliyodan B, Nguyen HT (2006) Understanding regulatory networks and engineering for enhanced drought tolerance in plants. Curr Opin Plant Biol 9:189-195. doi:10.1016/.jpbi.2006.01.019

Van Damme EJM, Barre A, Rouge P, Peumans WJ (2004) Cytoplasmic/nuclear plant lectins: a new story. Trends Plant Sci 9:484-489. doi:10.1016/j.tplants.2004.08.003

Vashisht AA, Tuteja N (2006) Stress responsive DEAD-box helicases: a new pathway to engineer plant stress tolerance. J Photoch Photobio B 84:150160. doi:10.1016/j.jphotobiol.2006.02.010

Vincent D, Lapierre C, Pollet B, Cornic G, Negroni L, Zivy M (2005) Water deficits affect caffeate O-methyltransferase, lignification, and related enzymes in maize leaves. A proteomic investigation. Plant Physiol 137:949-960, http://dx. doi.org/10.1104/pp.104.050815

Wen B, Nieuwland J, Murray JAH (2013) The Arabidopsis CDK inhibitor ICK3/KRP5 is rate limiting for primary root growth and promotes growth through cell elongation and endoreduplication. J Exp Bot 64:1135-1144. doi:10.1093/jxb/ert009 
Wu CM, Feng JJ, Wang R, Liu H, Yang HX, Rodriguez PL, Qin HJ, Liu X, Wang DW (2012) HRS1 acts as a negative regulator of abscisic acid signaling to promote timely germination of Arabidopsis seeds. PLoS One 7(4):e35764. doi: 10.1371/journal.pone.0035764

Yang SF, Hoffman NE (1984) Ethylene biosynthesis and its regulation in higher plants. Ann Rev Plant Physiol 35:155-189. doi:10.1146/annurev.pp. 35.060184.001103

Yang X, Yang YN, Xue LJ, Zou MJ, Liu JY, Chen F, Xue HW (2011) Rice ABI5-Like1 regulates abscisic acid and auxin responses by affecting the expression of ABRE-containing genes. Plant Physiol 156:1397-1409, http://dx.doi.org/10. 1104/pp.111.173427

Yazawa K, Jiang CJ, Kojima M, Sakakibara H, Takatsuji H (2012) Reduction of abscisic acid levels or inhibition of abscisic acid signaling in rice during the early phase of Magnaporthe oryzae infection decreases its susceptibility to the fungus. Physiol Mol Plant Pathol 78:1-7. doi:10.1016/j.pmpp.2011.12.003

Yoshida T, Mogami J, Yamaguchi-Shinozaki K (2014) ABA-dependent and ABAindependent signaling in response to osmotic stress in plants. Curr Opin Plant Biol 21:133-139. doi:10.1016/j.pbi.2014.07.009

Zhu MK, Chen GP, Dong TT, Wang LL, Zhang JL, Zhao ZP, Hu ZL (2015) SIDEAD31, a putative DEAD-Box RNA helicase gene, regulates salt and drought tolerance and stress-related genes in tomato. PLoS One 10(8): e0133849. doi:10.1371/journal.pone.0133849doi:10.1371/journal.pone.0133849

\section{Submit your manuscript to a SpringerOpen ${ }^{\odot}$ journal and benefit from:}

- Convenient online submission

- Rigorous peer review

- Immediate publication on acceptance

- Open access: articles freely available online

- High visibility within the field

- Retaining the copyright to your article

Submit your next manuscript at $\boldsymbol{s p r i n g e r o p e n . c o m ~}$ 